\title{
Effects of turbulence and temperature fluctuations on knock development in an ethanol/air mixture
}

\author{
Minh Bau Luong • Swapnil Desai • Francisco E. Hernández Pérez • \\ Ramanan Sankaran • Bengt Johansson • Hong G. Im
}

Accepted: 15 May 2020

\begin{abstract}
The effects of turbulence on knock development and intensity for a thermally inhomogeneous stoichiometric ethanol/air mixture at a representative end-gas autoignition condition in internal combustion engines are investigated using direct numerical simulations (DNS) with a skeletal reaction mechanism. Twoand three-dimensional simulations are performed by varying the most energetic length scale of temperature, $l_{T}$, and its relative ratio with the most energetic length scale of turbulence, $l_{T} / l_{e}$, together with two different levels of the turbulent velocity fluctuation, $u^{\prime}$. It is found that $l_{T} / l_{e}$ and the ratio of ignition delay time to eddyturnover time, $\tau_{i g} / \tau_{t}$, are the key parameters that control the detonation development. An increase in either $l_{T}$ or $l_{e}$ enhances the detonation propensity by allowing a longer run-up distance for the detonation development. The characteristic length scale of the temperature field, $l_{T}$, is significantly modified by high turbulence intensity achieved by a large $l_{e}$ and $u^{\prime}$. The intense turbulence mixing effectively distributes the initial temperature field to broader scales to support the developing detonation waves, thereby increasing the likelihood of the detonation formation. On the contrary, high
\end{abstract}

Minh Bau Luong · Francisco E. Hernández Pérez · Bengt Johansson · Hong G. Im

Clean Combustion Research Center (CCRC), 4700 King Abdullah University of Science and Technology, Thuwal 239556900, Kingdom of Saudi Arabia

E-mail: minhbau.luong@kaust.edu.sa, hong.im@kaust.edu.sa

Swapnil Desai

Bredesen Center for Interdisciplinary Research and Graduate Education, University of Tennessee, Knoxville, TN 379963394 , USA

Ramanan Sankaran

Computational Sciences and Engineering, Oak Ridge National Laboratory, Oak Ridge, TN 37831, USA turbulence intensity with a short mixing time scale, achieved by a small $l_{e}$ and a large $u^{\prime}$, reduces the superknock intensity attributed to the finer broken-up structures of detonation waves. Either $\tau_{i g} / \tau_{t}$ less than unity or $l_{e}=l_{T}$ even with a large $u^{\prime}$ is found to have no significant effect on super-knock mitigation. Finally, high turbulent intensity may induce high-pressure spikes comparable to the von Neumann spike. Increased temperature and pressure by combustion heating, noticeably after the peak of heat release rate, significantly enhance the collision and interaction of multiple emerging autoignition fronts near the ending combustion process, resulting in localized high-pressure spikes.

Keywords Direct numerical simulation (DNS) . super-knock · end-gas autoignition · temperature inhomogeneities · ethanol · deflagration to detonation transition (DDT)

\section{Introduction}

Downsized and boosted internal combustion (IC) engines provide higher thermal efficiency and lower emissions compared with the conventional IC engines. However, the elevated pressure and temperature of the incylinder fuel/air mixture under the high-load operating conditions may induce undesired pre-ignition, knock, and even super-knock phenomena [1]. Such abnormal combustion phenomena are also encountered in shock tubes, rapid compression machines, and gas turbine engines $[1,2]$. Super-knock is featured by excessive pressure oscillations and extremely high pressure spikes that may lead to mechanical failure. Experiments reported that a piston breaks at pressures exceeding 500 bar in the groove above the upper piston ring and may also be overheated due to the dramatically increased heat 


\section{Nomenclature}

0-D, 1-D, 2-D, \& 3-D Zero-dimensional, one-dimensional, two-dimensional, and

DNS three-dimensional

Direct numerical simulation

ICE Internal combustion engine

LIF Laser-induced fluorescence

HCCI Homogeneous-charge compression ignition

HRR Heat release rate

NTC Negative-temperature coefficient

RMS Root mean square

SI Spark-ignited

PDF Probability density function

\section{Symbols}

$a$

$\mathrm{BL}$

L, E, and G

$(.)_{l_{T}}^{l_{e}}$

$F_{H}$

$F_{C J}$

$F_{V N}$

$l_{t}$

$l_{T}$

$\phi^{\prime}$

$P_{C J}$

$P_{e}$

$P_{\max }$

$P_{V N}$

$\dot{q}$

$S_{L}$

$S_{s p}$

$\tau_{i g}$

$\tau_{i g}^{0}$

$\tau_{\text {ex }}$

$T, P$, and $\phi$

$T_{0}$

$T^{\prime}$

$P_{0}$

$\xi$

$u^{\prime}$

$V_{C J}$
Sound speed

Baseline cases with no turbulence

Denote three levels of $\tau_{i g} / \tau_{t}$ being less than, equal to, and greater than unity, respectively

The subscript and superscript correspond to the most energetic length scale of temperature, $l_{T}$, and turbulent velocity field, $l_{e}$, respectively.

Fraction of HRR of the regions with pressure greater than $P_{e}$

Fraction of HRR of the regions with pressure greater than

$P_{C J}$

Fraction of HRR of the regions with pressure greater than

$P_{V N}$

The most energetic length scale of turbulence

The most energetic length scale of temperature

Initial mean equivalence ratio

Root mean square (RMS) equivalence ratio fluctuation

Chapman-Jouguet pressure

Homogeneous constant-volume equilibrium pressure

Maximum pressure over the computational domain

Von Neumann pressure (spike)

Heat release rate

Laminar flame speed

Spontaneous ignition front speed

Ignition delay time

Zero-dimensional homogeneous ignition delay time

Excitation time

Temperature, pressure, and equivalence ratio

Initial mean temperature

Root mean square (RMS) temperature fluctuation

Initial mean pressure

Non-dimensional number defined as the ratio of the speed of sound to the spontaneous ignition front speed, $\xi=$ $a / S_{s p}$

Root mean square (RMS) velocity fluctuation

Non-dimensional number defined as the ratio of the acoustic residence time, $r_{h s} / a$, within the hot spot with a radius $r_{h s}$, to the excitation time, $\tau_{e x}, \varepsilon=\left(r_{h s} / a\right) / \tau_{e x}$

Chapman-Jouguet speed transfer with the breakdown of the thermal boundary layer [1]. The knock amplitude is found to increase with advanced ignition timing in spark-ignition engines, and if a pre-ignition event occurs, the spark timing can no longer be used to prevent the knock.

Once triggered by local hot spots and surfaces, the subsequent development of knock and super-knock depends on the mixture inhomogeneities in temperature and composition. Zeldovich [3] provided a theoretical framework to classify different ignition regimes based on the speed of a spontaneous ignition front, defined by the spatial gradient of the ignition delay time, $S_{s p}=$ $\left|\nabla \tau_{i g}\right|^{-1}$, relative to the deflagration front and sound speed.

Urtiew and Oppenheim [4] experimentally observed different modes of transition to detonation in an explo- 
sive gas with velocity and scalar fluctuations. In another study, Meyer and Oppenheim [5] proposed a model to demarcate the boundary between a stable detonation and a weak auto-ignition, and suggested a threshold value of $\partial \tau_{i g} / \partial T$ of $-2 \mu \mathrm{s} / \mathrm{K}$ for $\mathrm{H}_{2} / \mathrm{O}_{2}$ mixtures. The model was then numerically validated by Lutz et al. [6], and the hot-spot size of ignition kernels, and the excitation time were found to be two important parameters affecting detonation formation $[5,6]$.

Bradley and coauthors [7,8] identified different combustion modes in terms of two key dimensionless parameters: $\xi=a / S_{s p}$, the ratio of the speed of sound to the spontaneous ignition front speed, and $\varepsilon=\left(r_{h s} / a\right) / \tau_{e x}$ the ratio of the acoustic residence time, $r_{h s} / a$, within the hot spot with a radius $r_{h s}$, to the excitation time, $\tau_{e x}$, defined as the heat release time interval $[5,6]$.

The diagram has been widely adopted to determine the detonation conditions for different fuels with good prediction $[9,10,2,11,12,13,14,15,16,17,18,19,20]$. The effects of multiple hot spots in terms of their size and separation distance have also been investigated in onedimensional (1-D) configurations [18,15]. Similarly, recent studies $[21,22]$ have demonstrated that combustion behavior under modern IC engine conditions may exhibit an intricate interplay between deflagration, autoignition, and spontaneous propagation modes, wherein the level of complexity depends on the length/timescales of fluctuations in temperature and composition within the reactant mixture, which affect the time scales of the flame-ignition interaction. Consequently, knock/superknock formation may occur under certain conditions.

Most previous computational studies are largely limited to a simplified 1-D detonation configuration, thus lacking in the realistic multi-dimensional effects associated with the interactions of temperature and velocity fluctuations that may involve multiple detonation wave interactions [23,24]. Multi-dimensional DNS studies have mostly been undertaken on the autoignition characteristics only, without realization of detonation developments $[25,26,27,28,29,30,31,32,33,34,35$, $36,37,38,39,40,41]$. In these studies, a key issue was to identify the ignition characteristics, which was further developed into the ignition regime diagram $[42$, $43]$ to predict the occurrence of strong and weak ignition modes in the presence of temperature and turbulence fluctuations. Further extension of the ignition regime identification to temperature and composition fluctuations has been proposed and validated $[44,45$, 46]. In previous multi-dimensional DNS studies, the importance of the ratio of the length scale of temperature fluctuation to that of turbulence, $l_{T} / l_{e}$, as well as the ratio of the turbulent eddy turnover time, $\tau_{t}=l_{e} / u^{\prime}$, to the ignition delay time, $\tau_{i g}$, has been reported $[30,37]$.
Similar behavior may be anticipated in their effects on the detonation development.

A few studies have attempted to examine how turbulence affects the intensity of the developing detonation. Wei et al. $[47,48,49]$ used reduced-order turbulent models and found that increased turbulence intensity inhibits autoignition formation and reduced hot spot sizes, leading to different autoignition modes and knock intensities. Zhang et al. [50] studied the interaction of turbulent transport and low-temperature chemistry on knocking formation of an imposed hot spot. They found that fast turbulent mixing can inhibit autoignition to detonation transition, consistent with previous studies $[30,37,39]$, and a larger turbulent mixing scale can reduce the knocking strength attributed to broader mixing in the preheated zone in front of detonation waves. However, a few cases with a limited domain size were examined [50], and the developing detonation may originate from the bulk mixture itself, not necessarily induced by an imposed hot spot.

Recently, Towery and coauthors [51] proposed a statistical model to predict the detonability degree of an autoignitive gas with the thermodynamic gradients induced by compressible homogeneous isotropic turbulence (HIT) fluctuations, and validated the model with the DNS results, showing a good agreement. Our recent DNS study [52] with varying $l_{T}$ and the root-meansquare temperature fluctuation levels, $T^{\prime}$, found that $l_{T}$ is the key factor affecting the knock intensity, i.e., increasing $l_{T}$ significantly increases the peak pressure by allowing a longer run-up time. As a first attempt, however, the effects of different scales of temperature fluctuations were investigated without an additional turbulence mixing. As an extension to represent more general turbulent combustion applications, the combined effects of temperature and velocity fluctuations are now considered.

Therefore, the objective of this study is to investigate how turbulence affects the detonation intensity of the bulk mixture by systematically varying the ratio of $l_{T} / l_{e}$ and turbulent velocity fluctuations, $u^{\prime}$, with three different $l_{T}$, using multi-dimensional direct numerical simulations. Ethanol is adopted as a fuel in this study. Different statistical metrics are adopted to characterize the knock intensity, and their correlation with knock intensity is examined.

Ethanol is chosen as a representative non-NTC renewable biodiesel. Ethanol has been extensively studied by both experiments and modeling such that the chemical kinetic mechanism of ethanol is more reliable compared to higher hydrogen fuels. Additionally, it has been widely used in ICE research due to its high resistance to knock. However, ethanol exhibits a high tendency to 
pre-ignition [53], which has been linked with its small flame thickness, high laminar flame speed, and surface ignition tendency [2]. Undesirable pre-ignition phenomena stochastically occur in spark-ignited (SI) engines. The uncontrolled early flame development increases the temperature and pressure of the end-gas that may induce a strong end-gas auto-ignition process, even superknock under high-load and/or high-temperature conditions [53,2]. Therefore, the end-gas auto-ignition phenomena in the SI engine conditions are investigated.

\section{Methodology}

\subsection{Numerical methods and initial conditions}

The KAUST Adaptive Reacting Flow Solver (KARFS) $[54,55]$ is used to solve the fully compressible NavierStokes, species, and energy equations for gaseous mixtures. The diffusive terms are discretized using an eighthorder finite-difference scheme, while the convective terms are discretized using a seventh-order mapped weighted essentially non-oscillatory scheme along with local LaxFriedrich flux splitting to capture shocks and detonation waves. The solution is advanced in time using a second-order operator-splitting strategy with a fourthorder explicit Runge-Kutta method for transport and variable-order backward differentiation formulas [56] for chemistry. Periodic boundary conditions are imposed in all directions to represent constant volume ignition. In this study, ethanol is selected as a fuel because it is known to exhibit a high pre-ignition tendency despite its high resistance to knock. A skeletal mechanism of 40 species and 576 reactions is adopted for ethanol ignition and combustion [34], which has been validated over a wide range of equivalence ratios, pressure, and temperature conditions.

The high likelihood of pre-ignition for ethanol is attributed to its small flame thickness and high laminar flame speed [2]. In general, the knock amplitude in an SI engine increases with advanced ignition timing and is significantly enhanced if a pre-ignition event occurs. Early pre-ignition increases both the temperature and pressure of the unburnt mixture, facilitating the endgas autoignition that can lead to detonation. As such, a high initial mean temperature, $T_{0}$ of $1200 \mathrm{~K}$, representing the end-gas autoignition conditions is chosen to increase the likelihood of detonation, and to reduce the computational cost. The initial and uniform equivalence ratio and pressure values, $\phi_{0}=1.0$ and $P_{0}=35.4$ bar, respectively, are chosen for all simulations to represent the conditions at the top dead center of an optical engine [57] that was designed to study knock.
Note that due to the large computational demand for DNS, the complex thermochemical and physical process throughout the entire engine cycle is not reproduced in this study. Only the end-gas autoignition process is simulated by considering the remaining unburnt fuel/air mixture already heated up to a high temperature and pressure. As such, the simulations only capture the onset of the end-gas autoignition event. Since the end-gas autoignition occurs at a very short time scale in order of microseconds, the entire process is assumed to occur at a constant volume adiabatic condition, thus neglecting the effect of the piston motion in this study.

The 0-D homogeneous ignition delay time, $\tau_{i g}^{0}$, excitation time (i.e. period of time from $5 \% \mathrm{HRR}_{\max }$ until the peak of HRR is reached), $\tau_{e x}$, and equilibrium pressure, $P_{e}$, of the stoichiometric ethanol/air mixture under a adiabatic condition with the initial temperature and pressure of $1200 \mathrm{~K}$ and 35.5 bar are $75 \mu \mathrm{s}$, $0.66 \mu \mathrm{s}$, and $100 \mathrm{bar}$, respectively. Other relevant ideal one-dimensional detonation parameters associated with this initial condition are the von Neumann pressure, $P_{V N}$ of 319 bar, Chapman-Jouguet pressure, $P_{C J}$ of 187 bar, and Chapman-Jouguet speed, $V_{C J}$ of 1836 $\mathrm{m} / \mathrm{s}$.

An initial homogeneous and isotropic field of random velocity fluctuations was prescribed using the PassotPouquet [58] kinetic energy spectrum function and superimposed on the mean velocity field for all the DNS cases. Likewise, the initial temperature fluctuations were generated by a scalar spectrum similar to the kinetic energy spectrum, and superimposed on a constant mean temperature field. Note that the two random fields are uncorrelated. For all DNS cases, an initial root-meansquare (RMS) temperature fluctuation, $T^{\prime}$ of $15 \mathrm{~K}$, is chosen which is comparable to the experimental value of $13.3 \mathrm{~K}$ that was observed in a HCCI engine [59]. The initial range of variation for the temperature field is approximately $100 \mathrm{~K}$, which is commonly observed in IC engines and rapid compression machines (RCM) [60,61, $62,63]$. The selected $T^{\prime}$ and $l_{T}$ are quantitatively comparable with the experimental results [64] using twodimensional laser-induced fluorescence (LIF) measurement, i.e., the temperature fluctuations in the order of $20 \mathrm{~K}$ with their geometrical size ranging from $1 \mathrm{~mm}$ to $10 \mathrm{~mm}$. This is consistent with the experiment by Kaiser and coauthors [65], which reported that the standard deviation of temperature at the top dead center, $T^{\prime}$ of $9.2 \mathrm{~K}$, corresponds to $1.9 \%$ of the temperature difference between wall and bulk gas.

The most energetic length scale of turbulent velocity spectrum, $l_{e}$, and RMS velocity fluctuation, $u^{\prime}$, are important parameters to describe the flow field in an IC engine, with $l_{e}$ being controlled by the engine ge- 


\begin{tabular}{lcccccccc}
\hline Case & $\begin{array}{c}l_{T} \\
(\mathrm{~mm})\end{array}$ & $\begin{array}{c}l_{e} \\
(\mathrm{~mm})\end{array}$ & $\begin{array}{c}u^{\prime} \\
(\mathrm{m} / \mathrm{s})\end{array}$ & $\tau_{i g} / \tau_{t}$ & $\begin{array}{c}F_{H} \\
\left(\times 10^{-2}\right)\end{array}$ & $\begin{array}{c}F_{C J} \\
\left(\times 10^{-2}\right)\end{array}$ & $\begin{array}{c}F_{V N} \\
\left(\times 10^{-2}\right)\end{array}$ & $\begin{array}{c}\text { Domain size } \\
(\mathrm{mm})\end{array}$ \\
\hline $\mathrm{BL}_{1}$ & 1 & - & - & - & 6.4 & 0 & 0 & $8 \times 8$ \\
$\mathrm{E}_{1}^{1}$ & 1 & 1 & 16.6 & 1.0 & 6.6 & 0 & 0 & $8 \times 8$ \\
$\mathrm{G}_{1}^{1}$ & 1 & 1 & 83.3 & 5.0 & 13.5 & 0.5 & 0 & $8 \times 8$ \\
$\mathrm{~L}_{1}^{5}$ & 1 & 5 & 16.6 & 0.2 & 6.3 & 0 & 0 & $20.48 \times 20.48$ \\
$\mathrm{E}_{1}^{5}$ & 1 & 5 & 83.3 & 1.0 & 25.2 & 4.7 & 1.5 & $20.48 \times 20.48$ \\
\hline $\mathrm{BL}_{2}$ & 2 & - & - & - & 29.2 & 13.3 & 7.1 & $8 \times 8$ \\
$\mathrm{E}_{2}^{1}$ & 2 & 1 & 16.6 & 1.0 & 19.0 & 2.0 & 0 & $8 \times 8$ \\
$\mathrm{G}_{2}^{1}$ & 2 & 1 & 83.3 & 5.0 & 18.6 & 1.8 & 0.3 & $8 \times 8$ \\
\hline $\mathrm{BL}_{5}$ & 5 & - & - & - & 61.7 & 41.6 & 19.2 & $20.48 \times 20.48$ \\
$L_{5}^{5}$ & 5 & 5 & 16.6 & 0.2 & 58.8 & 37.2 & 18.4 & $20.48 \times 20.48$ \\
$\mathrm{E}_{5}^{5}$ & 5 & 5 & 83.3 & 1.0 & 47.6 & 24.0 & 11.4 & $20.48 \times 20.48$ \\
$\mathrm{E}_{5}^{1}$ & 5 & 1 & 16.6 & 1.0 & 49.1 & 25.5 & 12.0 & $20.48 \times 20.48$ \\
$\mathrm{G}_{5}^{1}$ & 5 & 1 & 83.3 & 5.0 & 33.5 & 8.3 & 2.8 & $20.48 \times 20.48$ \\
\hline $\mathrm{BL}_{2} 3 \mathrm{D}$ & 2 & - & - & - & 14.5 & 4.6 & 1.6 & $10.24 \times 10.24 \times 10.24$ \\
$\mathrm{E}_{2}^{1} 3 \mathrm{D}$ & 2 & 1 & 16.6 & 1.0 & 23.0 & 5.0 & 0.8 & $10.24 \times 10.24 \times 10.24$ \\
$\mathrm{BL}_{5} 3 \mathrm{D}$ & 5 & - & - & - & 58.7 & 41.0 & 10.9 & $20.48 \times 10.24 \times 10.24$ \\
$\mathrm{E}_{5}^{1} 3 \mathrm{D}$ & 5 & 1 & 16.6 & 1.0 & 49.0 & 29.5 & 10.0 & $20.48 \times 10.24 \times 10.24$ \\
$\mathrm{G}_{5}^{1} 3 \mathrm{D}$ & 5 & 1 & 83.3 & 5.0 & 57.9 & 32.1 & 3.9 & $20.48 \times 10.24 \times 10.24$ \\
\hline
\end{tabular}

Table 1: Physical parameters of 2-D and 3-D DNS cases. L, E, and G denote three levels of $\tau_{i g} / \tau_{t}$ being less than, equal to, and greater than unity, respectively. BL denotes a baseline case (no turbulence). The subscript and superscript correspond to the most energetic length scale of temperature, $l_{T}$, and turbulent velocity field, $l_{e}$, respectively. For example, $\mathrm{E}_{5}^{1}$ denotes a 2 -D case with $\tau_{i g} / \tau_{t}$ of $1, l_{T}$ of $5 \mathrm{~mm}$, and $l_{e}$ of $1 \mathrm{~mm}$.
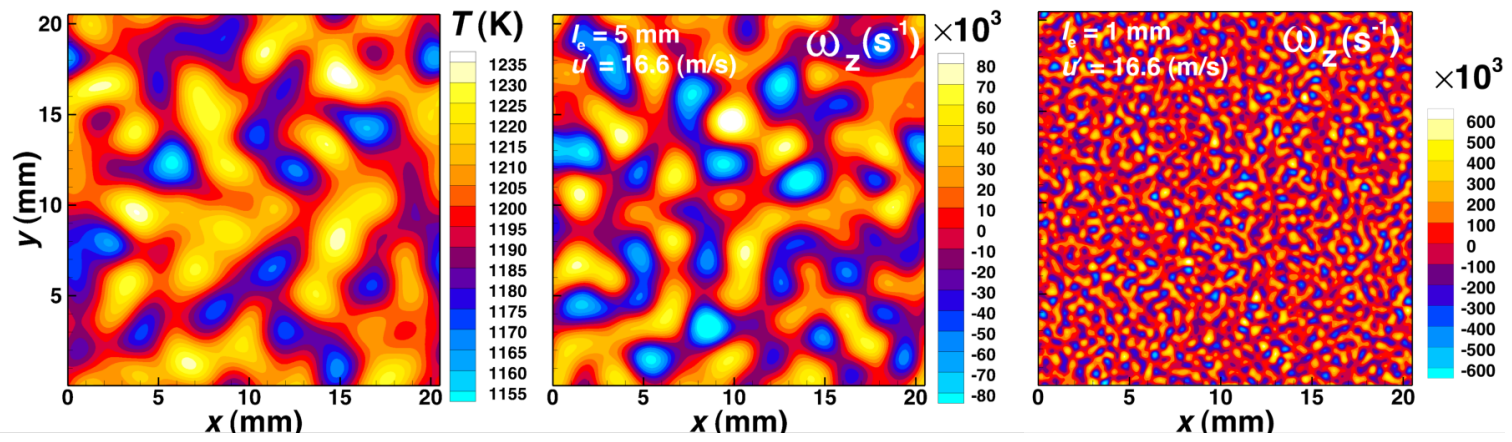

Fig. 1: Representative contours of temperature with $T^{\prime}$ of $15 \mathrm{~K}$, and vorticity for $l_{e}$ of $5 \mathrm{~mm}$ (second column) and $1 \mathrm{~mm}$ (third column) with $u^{\prime}$ of $16.6 \mathrm{~m} / \mathrm{s}$. Note that the computational domain of $20.48 \times 20.48 \mathrm{~mm}^{2}$ covers approximately four $l_{e}$ of $5.0 \mathrm{~mm}$, and twenty $l_{e}$ of $1.0 \mathrm{~mm}$ in each direction.

ometry and the large-scale structures that shed from the intake jet flows. Both $l_{e}$ and $u^{\prime}$ vary over a range of crank angles, engine speeds, intake pressures, intake port geometries and orientations, piston shapes, tumble-based or swirl-based designs $[66,67,68,69,70]$. Additionally, there may be at least two different integral length scales: one in the radial direction and the other one along the axis of piston motion $[70,68,69]$. Due to the importance of both parameters, the effect of $l_{e}$ and $u^{\prime}$ variation on knock formation is examined in this study. Three different $l_{e}$ values of $1 \mathrm{~mm}, 2 \mathrm{~mm}$, and $5 \mathrm{~mm}$ are chosen, which lie within the same order of magnitude of $l_{e}$ measured in IC engines [66,67, $68,69,70]$. Note that the most energetic length scale corresponds to the wavelength in the energy spectrum where the kinetic energy is maximum. The correspond- ing two-point autocorrelation integral scales for three most energetic length scales of $1.0 \mathrm{~mm}, 2 \mathrm{~mm}, 5 \mathrm{~mm}$ are approximately $0.2 \mathrm{~mm}, 0.4 \mathrm{~mm}, 1.0 \mathrm{~mm}$, respectively. The computational domain of $20.48 \times 20.48 \mathrm{~mm}^{2}$ is sufficiently large to accommodate four integral scale eddies in the largest condition of $l_{e}=5.0 \mathrm{~mm}$ in order to reproduce statistically significant behavior.

Since the ratio $\tau_{i g} / \tau_{t}$ has been found to play a key role in the evolution of the combustion process $[42,39]$, three $\tau_{i g} / \tau_{t}$ levels of $0.2,1.0$ and 5.0 are studied. Note that although the associated $u^{\prime}$ values of $16.6 \mathrm{~m} / \mathrm{s}$ and $83.3 \mathrm{~m} / \mathrm{s}$ are one order of magnitude greater than those typically observed in IC engines, such levels of $u^{\prime}$ allow us to examine to what extent turbulence affects the developing detonation process. Although a short $\tau_{i g}$ resulting in a large $u^{\prime}$ is selected to save the com- 
putational cost, the selected conditions are still relevant to the SI engines by preserving the relevant length and time-scale ratios $[27,30]$. By a theoretical scaling analysis, and validated by a systematically parametric set of DNS cases, the previous studies [27,30,37,42,44] found that the flame-turbulence interaction can be understood in terms of relevant length and time-scale ratios of the turbulent flow structure compared with those of the flame. Particularly, $\tau_{i g} / \tau_{t}$ and $l_{T} / l_{e}$ were found to be the key parameters instead of their absolute values (i.e., $\tau_{i g}, u^{\prime}, l_{e}$ and $l_{T}$ ). Details of the physical and numerical parameters for the eighteen cases are listed in Table 1. Representative initial 2-D fields of temperature and vorticity are shown in Fig. 1.

\subsection{Quantitative analysis}

Three metrics are adopted to assess the knock intensity, which are defined as follows [52]:

$F_{H}=\frac{\sum\left\langle\dot{q} \mid P>1.1 P_{e}\right\rangle}{\sum \dot{q}}$,

$F_{C J}=\frac{\sum\left\langle\dot{q} \mid P>P_{C J}\right\rangle}{\sum \dot{q}}$,

$F_{V N}=\frac{\sum\left\langle\dot{q} \mid P>P_{V N}\right\rangle}{\sum \dot{q}}$,

where the summation is operated over the total number of computational cells in the DNS domain, $\dot{q}$ is the HRR, while $P_{e}, P_{C J}$ and $P_{V N}$ correspond to the homogeneous constant-volume equilibrium pressure, the Chapman-Jouguet pressure, and the von Neumann pressure, respectively, computed at the given initial conditions of $T_{0}, P_{0}$, and $\phi_{0}$. Note that $F_{H}, F_{C J}$, and $F_{V N}$ values in Table 1 and Fig. 13 are time-integrated quantities. $F_{H}, F_{C J}$ and $F_{V N}$ range from zero to unity. The threshold values of $1.1 P_{e}, P_{C J}$ and $P_{V N}$ are selected such that $F_{H}$ measures the HRR fraction of the regions at above-equilibrium ignition pressure, while $F_{V N}$ $\left(F_{C J}\right)$ quantifies the HRR fraction of the regions at high-pressure (low-pressure) detonation level. Note that the threshold value of $1.1 P_{e}$ is arbitrarily chosen [51], but we have confirmed that the results are insensitive to the choice of the threshold value.

\section{Results and discussion}

\subsection{Effect of $l_{T}$ : baseline cases}

In this sub-section, the baseline cases with a quiescent initial velocity field are discussed. The temporal evolution of the normalized $P_{\max }$, and the probability density functions (PDF) of $\xi$ are shown in Fig. 2. The contours of temperature, pressure, and HRR at the time of the peak of $F_{H}$ for these baseline cases are shown in Fig. 3. By fixing $T^{\prime}$ of $15 \mathrm{~K}$, increasing $l_{T}$ from $1 \mathrm{~mm}$ to $5 \mathrm{~mm}$ decreases $|\nabla T|$, which in turn decreases $\xi\left(\xi=a /\left|\frac{d \tau_{i g}}{d T} \nabla T\right|^{-1}\right)$, resulting in a shift of the $\mathrm{PDF}$ of $\xi$ toward the developing detonation regime (see Fig. 2). Consequently, BL5 is more prone to developing detonation as compared to BL1 and BL2. Consistent with the PDFs of $\xi, P_{\max } \leq P_{V N}$ for BL1, confirming that this condition corresponds to a spontaneous ignition process with much larger values of $\xi$. By increasing $l_{T}$ from $1 \mathrm{~mm}$ to $2 \mathrm{~mm}$, a weak detonation process is observed near the end of the ignition process for BL2 $\left(F_{V N} \approx 0.07\right.$ and 0.2 for BL2 and BL5, respectively, as listed in Table 1). While the distribution of $\xi$ is still mostly larger than 10, a sufficient amount of the unburnt mixture remains during the developing detonation phase (see Fig. 3) such that BL2 eventually reaches the detonation level. BL5 exhibits the strongest detonation as depicted in the temporal evolution of $P_{\max }$ much higher than $P_{V N}$ (see Fig. 2). The fact that $P_{\max }$ exceeds $P_{V N}$ indicates that there is a shock-to-shock interaction, as also evidenced in Fig. 3, leading to the additional instantaneous pressure rise, signifying a knock event. Figure 2 also reveals that $P_{\max }$ of the $3-\mathrm{D}$ cases has comparable levels of amplitude as compared to the 2-D counterparts; however, the duration of detonation occurrence of the $3-\mathrm{D}$ cases is shorter. A quantitative evaluation of detonation intensity is presented in Section 3.5. In our previous study [52] without turbulence effects, no detonation was observed with $l_{T}$ as small as $1 \mathrm{~mm}$ for $T^{\prime}$ over a wide range from $0.5 \mathrm{~K}$ to $20 \mathrm{~K}$. Therefore, it was believed that a minimum size of $l_{T}$ was needed so that a sufficient amount of unburned reactants allows a sufficient run-up of detonation development [51]. As shown in Fig. 3, the onset of detonation waves is well established for BL5, while a significant amount of charge still remains unburned as visually seen by the low-temperature regions.

\subsection{Effect of turbulence: $l_{T}$ of $1 \mathrm{~mm}$}

With the understanding that increasing $l_{T}$ enhances the detonation development, we now investigate the additional effect of turbulent mixing as $l_{e}$ is varied relative to $l_{T}$. In this sub-section, the effect of increasing $l_{e}$ is investigated by superimposing turbulence on the BL1 case with $l_{T}=1 \mathrm{~mm}$. A set of four $2-\mathrm{D}$ simulations are performed by varying $l_{e}$ and $u^{\prime}$ to examine their effect on the knock intensity. The values $l_{e}$ of $1 \mathrm{~mm}$ and $5 \mathrm{~mm}$, and $u^{\prime}$ of $16.6 \mathrm{~m} / \mathrm{s}$ and $83.3 \mathrm{~m} / \mathrm{s}$ are chosen 

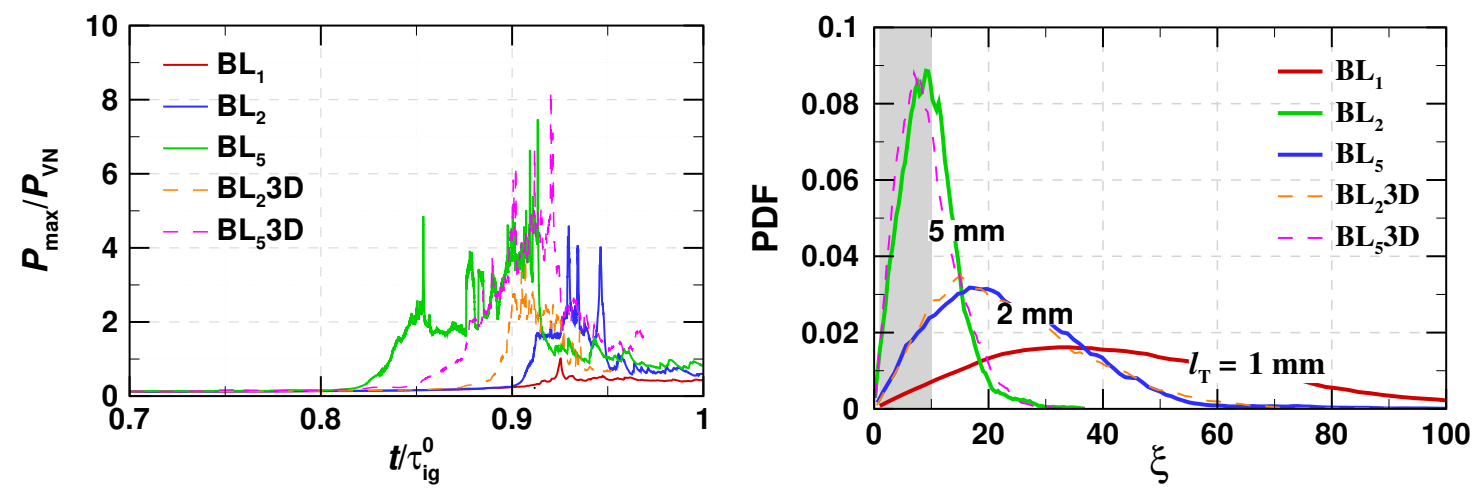

Fig. 2: Temporal evolution of the normalized maximum pressure, $P_{\max } / P_{V N}$, and the probability density functions (PDF) of $\xi$ for the baseline cases. The gray area in the PDF figure depicts the region of $1<\xi<10$ determined by a series of 1-D simulations under the same initial conditions, which is prone to developing detonation.

while fixing $l_{T}$ of $1 \mathrm{~mm}$ and $T^{\prime}$ of $15 \mathrm{~K}$. The temporal evolution of the normalized $P_{\max }$, and RMS pressure fluctuation, $P^{\prime}$, for four cases are plotted in Fig. 4. The contours of HRR, temperature, and pressure for cases $\mathrm{E}_{1}^{1}, \mathrm{G}_{1}^{1}, \mathrm{~L}_{1}^{5}$, and $\mathrm{E}_{1}^{5}$, are shown in Fig. 5. Three main points are made from these figures.

First, $\mathrm{E}_{1}^{5}$ is able to develop into detonation near the end of the ignition process as featured by its $P_{\max } \geq$ $P_{V N}$ (see Fig. 4) and much higher pressure variation, $P^{\prime}$. This is the consequence of the high turbulence intensity of $\mathrm{E}_{1}^{5}$ with a large $l_{e}$ (i.e., $l_{e}$ of $5 \mathrm{~mm}$ and $u^{\prime}$ of $83.3 \mathrm{~m} / \mathrm{s}, \tau_{i g} / \tau_{t}$ of 1.0 ) being able to significantly spread temperature inhomogeneities over a broad area, stretching out the length of the "dissipation elements" representing the average distance between the peak and trough of the temperature field [11], leading to a longer run-up distance for developing detonation. As shown in Fig. 5, at the onset of detonation for $\mathrm{E}_{1}^{5}$, a significant amount of the unburned mixture (low-temperature regions) still remains and is stretched over a wide area of the computational domain with a distance greater than the initial $l_{T}$ of $1 \mathrm{~mm}$, allowing more space to facilitate detonation formation.

Second, no detonation is observed for both cases with $l_{e}$ of $1 \mathrm{~mm}$ as their $P_{\max } \leq P_{V N}$, despite a few pressure spikes $\left(P\right.$ approximating $\left.P_{V N}\right)$ which result from the collision and interaction of autoignition waves. Figure 5 shows that the majority of the fuel/air mixture is consumed by propagating ignition fronts that annihilate the developing detonation.

Third, under the present autoignitive conditions, increasing turbulence intensity also increases the amplitude of the pressure spikes (collisions of propagating ignition fronts and/or growing ignition kernels), resulting in a higher pressure fluctuation as quantified by $P^{\prime}$ and the temporal evolution of $P_{\max }$ in Fig. 4, which is attributed to faster burning rates of turbulent corrugated ignition fronts $[37,39]$.

The above results suggest that, in addition to the high turbulence level by increased $u^{\prime}$, the relative ratio of $l_{e} / l_{T}$ plays a crucial role in affecting knock formation. In the next section, the effect of $l_{e} / l_{T}$ is further investigated.

\subsection{Effect of turbulence: $l_{T}$ of $5 \mathrm{~mm}$}

The previous sections demonstrate that $l_{T}$ and $l_{e}$ are the two key parameters associated with detonation formation. Either increasing $l_{T}$ or $l_{e}$ promotes the likelihood of detonation initiation. In this section, the possibility of $l_{e}$ on alleviating super-knock intensity is examined. Since case BL5 represents a strong detonation situation, it is adopted in this section as a baseline for comparison to turbulent cases with various $l_{e}$ and $u^{\prime}$. The set of cases includes $l_{e}$ of $1 \mathrm{~mm}$ and $5 \mathrm{~mm}$, and $u^{\prime}$ of $16.6 \mathrm{~m} / \mathrm{s}$ and $83.3 \mathrm{~m} / \mathrm{s}$, while fixing $l_{T}$ of $5 \mathrm{~mm}$ and $T^{\prime}$ of $15 \mathrm{~K}$. The temporal evolution of the normalized $P_{\text {max }}$ and RMS pressure fluctuation, $P^{\prime}$, for these cases are plotted in Fig. 6. The corresponding contours of $\mathrm{HRR}$, temperature, and pressure for cases $\mathrm{L}_{5}^{5}, \mathrm{E}_{5}^{5}$, and $\mathrm{G}_{5}^{1}$ are shown in Figs. 7-Fig. 9. Several observations are made from these figures.

First, for the two cases with $l_{e}$ of $5 \mathrm{~mm}, \mathrm{~L}_{5}^{5}$ and $\mathrm{E}_{5}^{5}$, increasing $u^{\prime}$ from $16.6 \mathrm{~m} / \mathrm{s}$ to $83.3 \mathrm{~m} / \mathrm{s}$ leads to a higher global peak pressure. For both $u^{\prime}$ levels, no noticeable reduction in the peak of $P_{\max }$ and $P^{\prime}$ is seen with respect to the baseline case (Fig. 6). For the small ratio of $\tau_{i g} / \tau_{t}$ ranging from 0.2 to 1.0 under consideration, prior to the onset of detonation there is no sufficient time for turbulence to significantly affect the detonation evolution. As shown in Fig. 7 and Fig. 8, turbulence weakly wrinkles and distorts ignition fronts, resulting in a slight increase in the area of mixtures 

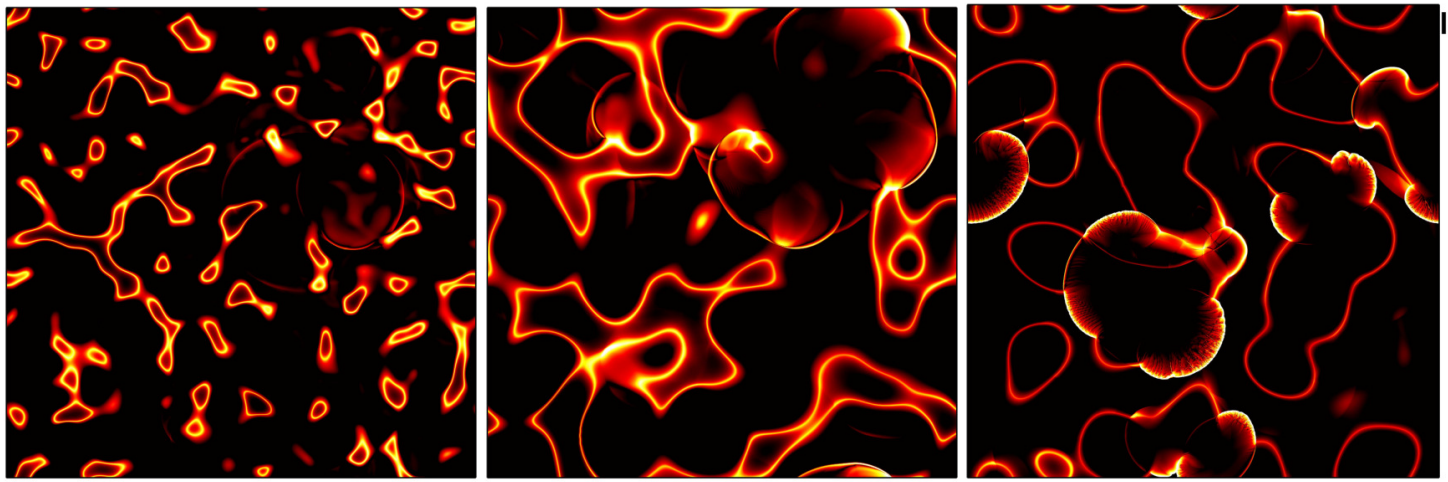

$\log (\mathrm{HRR})$
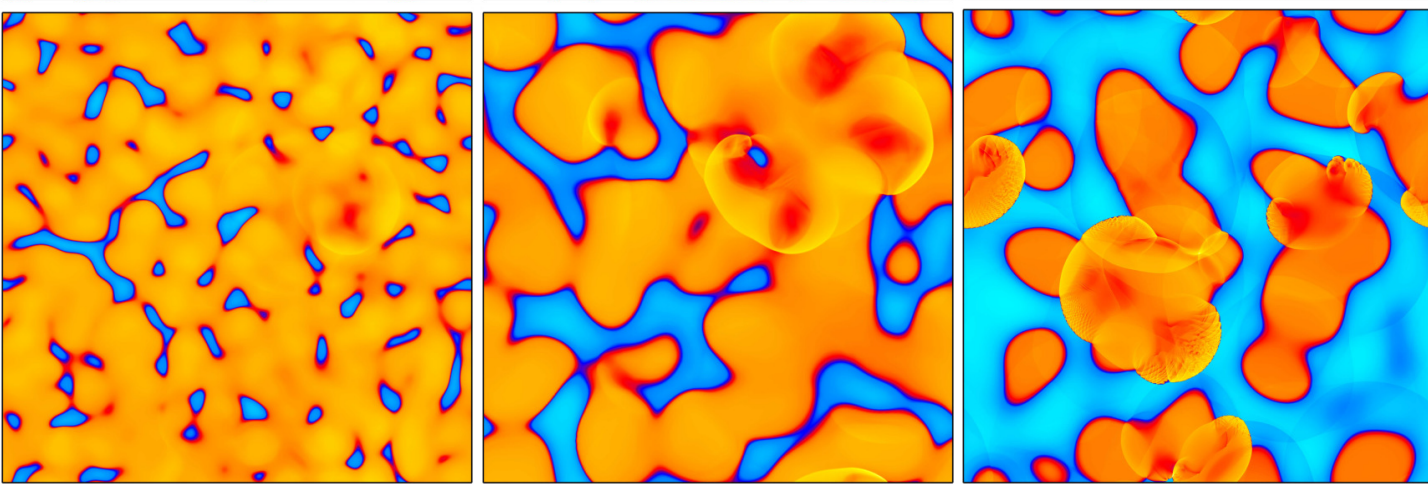

$T(\mathrm{~K})$
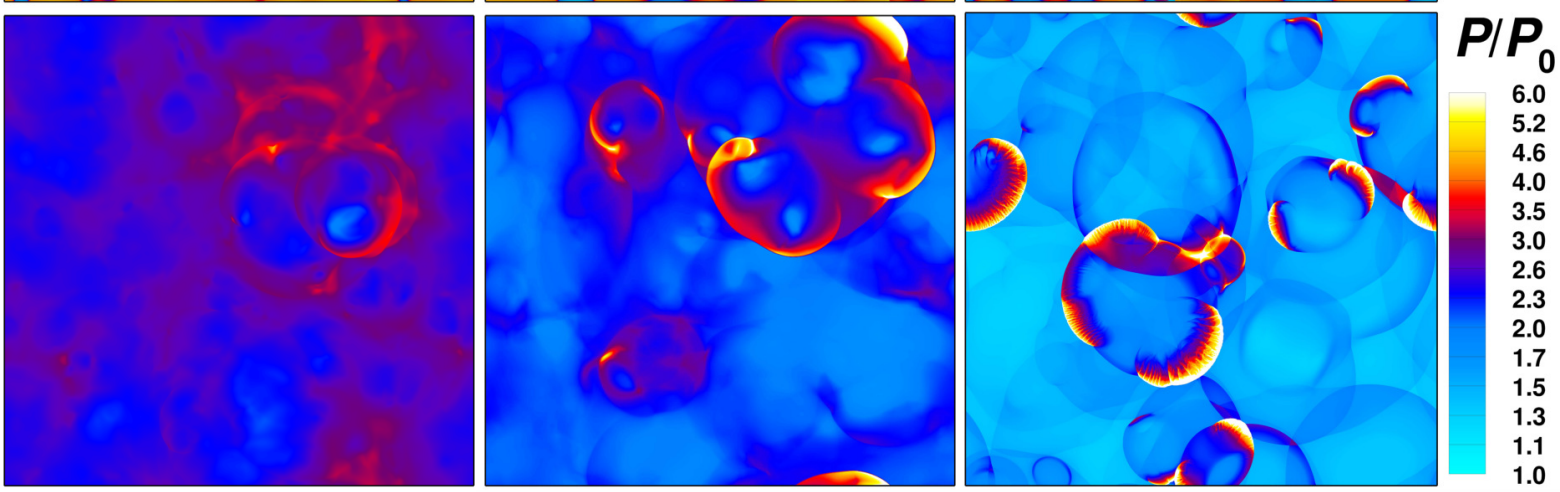

Fig. 3: Contours of HRR (top row), temperature (middle row), and pressure (bottom row) for three baseline cases, $\mathrm{BL}_{1}$ (first column), $\mathrm{BL}_{2}$ (second column), and $\mathrm{BL}_{5}$ (third column), with $l_{T}$ of $1 \mathrm{~mm}, 2 \mathrm{~mm}$, and $5 \mathrm{~mm}$, respectively. The domain size of $\mathrm{BL}_{1}$ and $\mathrm{BL}_{2}$ is $8 \times 8 \mathrm{~mm}^{2}$, while that of $\mathrm{BL}_{5}$ is $20.48 \times 20.48 \mathrm{~mm}^{2}$.

burnt by turbulent flames prior to the detonation initiation. Note that for $\mathrm{E}_{5}^{5}\left(u^{\prime}=83.3 \mathrm{~m} / \mathrm{s}\right)$, some hot spots are precluded from evolving into detonation waves as compared with BL5; however, finer detonation waves appear simultaneously during the developing detonation phase (see Fig. 9), subsequently colliding and interacting with each other to result in the high-pressure spikes that are seen in Fig. 6.

Second, two cases, $\mathrm{E}_{5}^{1}$ with $l_{e}$ of $1 \mathrm{~mm}$ and $u^{\prime}=$ $16.6 \mathrm{~m} / \mathrm{s}$ and $\mathrm{E}_{5}^{5}$ with $l_{e}$ of $5 \mathrm{~mm}$ and $u^{\prime}=83.3 \mathrm{~m} / \mathrm{s}$, have consistent combustion behavior in terms of detonation intensity (i.e., a comparable $F_{V N} \approx 0.12$ in Table 1). Both cases have no significant reduction in the peak of $P_{\max }$ and $P^{\prime}$ due to $\tau_{i g} / \tau_{t}$ of 1.0 , such that the turbulent time scale is not fast enough to significantly affect the initial temperature field and the combustion rate. However, increasing turbulent intensity results in a faster turbulence time scale (i.e., $\mathrm{G}_{5}^{1}$ with $u^{\prime}=83.3 \mathrm{~m} / \mathrm{s}$ and $\tau_{i g} / \tau_{t}=5$ ) that increases the area burned by corrugated turbulent flames and ignition fronts, and creates smaller and finer localized detonation waves during the developing detonation process due to a small $l_{e}$ of $1 \mathrm{~mm}$ (see Fig. 9). G $\mathrm{G}_{5}^{1}$ features a lower peak of $P^{\prime}$, and the duration of detonation is two times shorter than that of BL5, (see Fig. 6). Therefore, $F_{V N} \approx 0.03$ of $\mathrm{G}_{5}^{1}$ is much smaller than $F_{V N} \approx 0.20$ of BL5. 

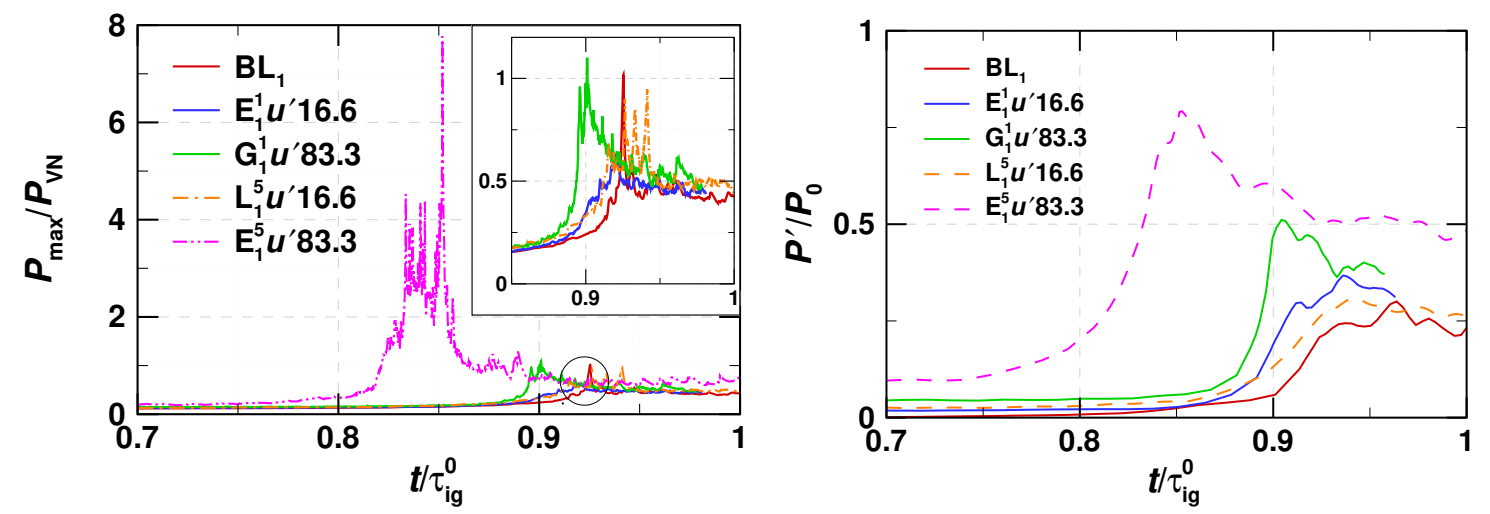

Fig. 4: Temporal evolution of the normalized maximum pressure, $P_{\max } / P_{V N}$, and the normalized root-mean-square pressure fluctuation, $P^{\prime} / P_{0}$ for all the cases with $l_{T}$ of $1 \mathrm{~mm}$.
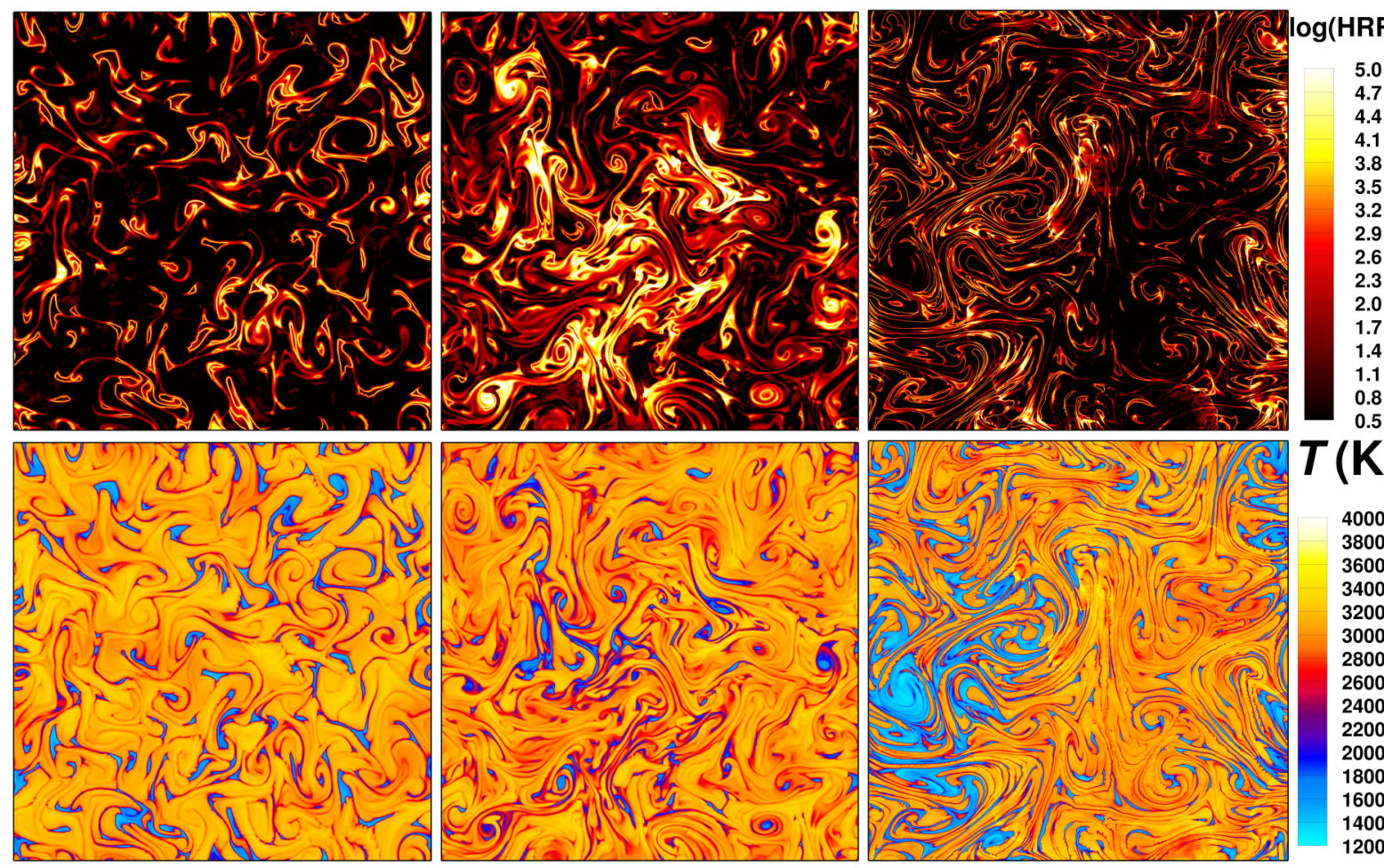

$T(\mathrm{~K})$
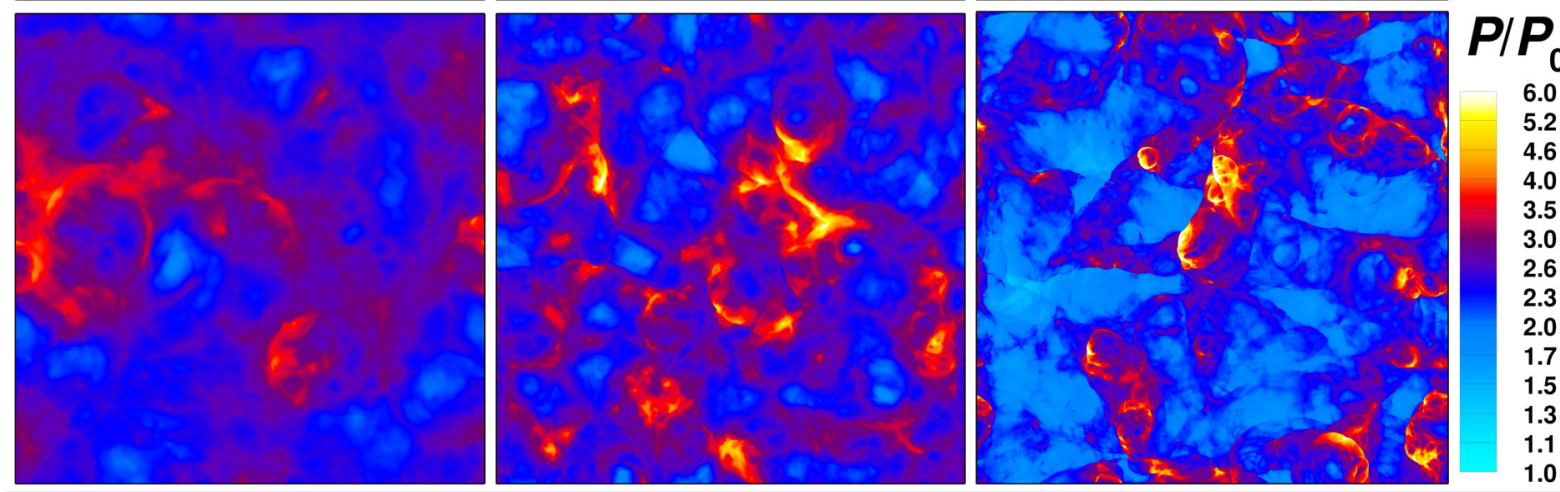

Fig. 5: Contours of HRR (top row), temperature (middle row), and pressure (bottom row) for cases $\mathrm{E}_{1}^{1}$ (first column), $\mathrm{G}_{1}^{1}$ (second column), and for $\mathrm{E}_{1}^{5}$ (third column). The domain size of $\mathrm{E}_{1}^{1}$ and $\mathrm{G}_{1}^{1}$ is $8 \times 8 \mathrm{~mm}^{2}$, while that of $\mathrm{E}_{1}^{5}$ is $20.48 \times 20.48 \mathrm{~mm}^{2}$. 

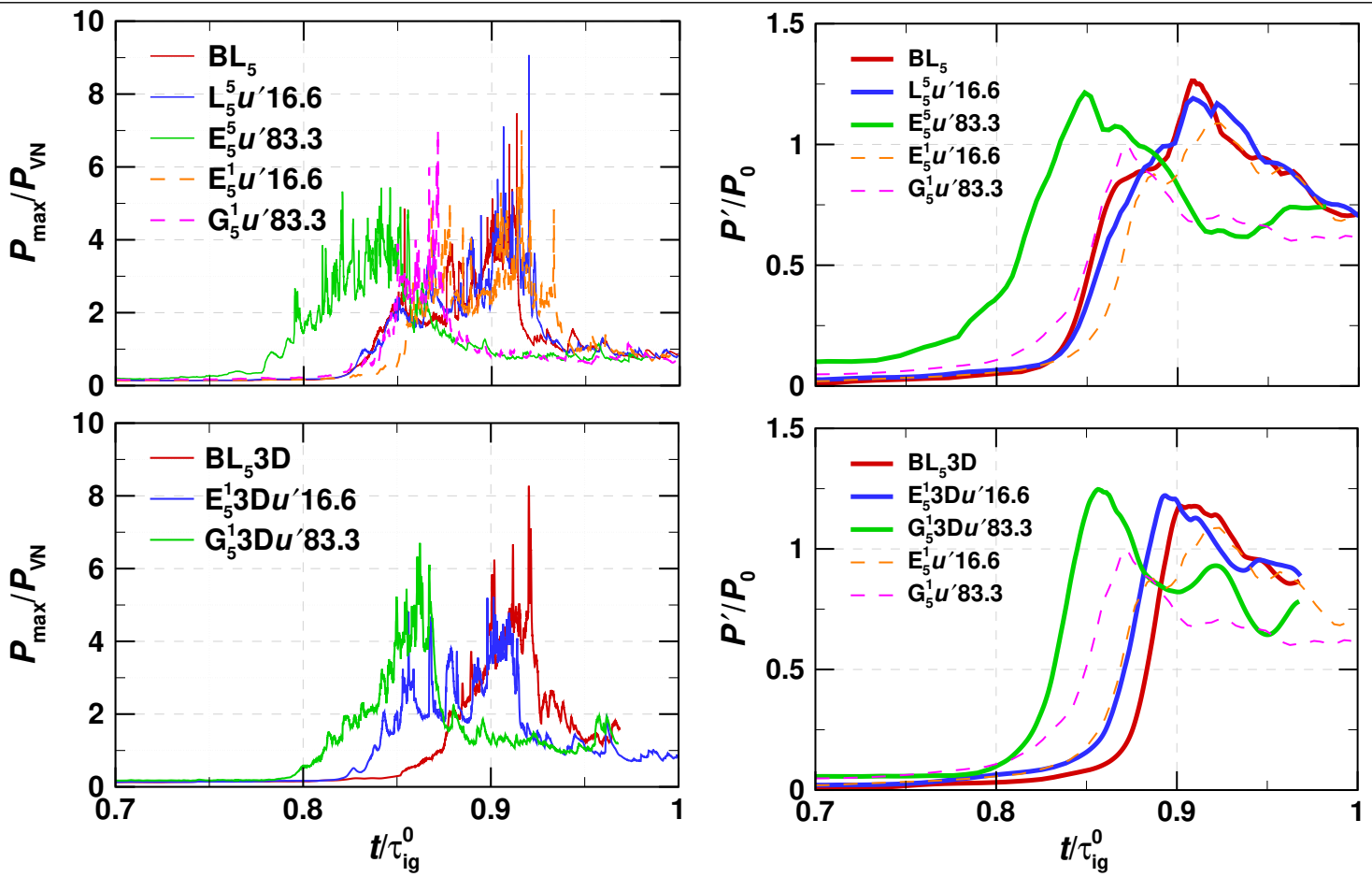

Fig. 6: Temporal evolution of the normalized maximum pressure, $P_{\max } / P_{V N}$ (first column), and normalized rootmean-square pressure fluctuation, $P^{\prime} / P_{0}$ (second column) for the cases with $l_{e}$ of $5 \mathrm{~mm}$.

Third, the results of the $2-\mathrm{D}$ and $3-\mathrm{D}$ cases show a consistent agreement in terms of the maximum pressure spikes, the duration of process with $P_{\max } \approx P_{V N}$, and the level of pressure variation, $P^{\prime}$, although the $3-\mathrm{D}$ cases exhibit a slightly higher spatial pressure oscillation during the intense detonation evolution as depicted by the maximum $P^{\prime}$ in Fig. 6 .

\subsection{Effect of turbulence: $l_{T}$ of $2 \mathrm{~mm}$}

As the baseline case BL2 exhibits a moderate detonation intensity (i.e., $F_{C J} \approx 0.13$ and $F_{V N} \approx 0.07$ ), high turbulence intensity may be able to suppress the developing detonation. This is investigated through an additional set of two 2-D simulations, $\mathrm{E}_{2}^{1}$ and $\mathrm{G}_{2}^{1}$, and one 3 -D simulation, $\mathrm{E}_{2}^{1} 3 \mathrm{D}$, with $l_{e}$ of $1 \mathrm{~mm}$. The temporal evolution of the normalized $P_{\max }$ and the root-meansquare pressure fluctuation $P^{\prime}$, for these cases are shown in Fig. 10. The results reveal that the developing detonation waves are attenuated by turbulent mixing as quantified by $F_{C J} \approx 0.02$ listed in Table 1 for both $\mathrm{E}_{2}^{1}$ and $\mathrm{G}_{2}^{1}$. Note that although $F_{C J}$ and $F_{V N}$ nearly vanish, high-pressure spikes $\left(P_{\max }>P_{V N}\right)$ are observed in Fig. 10. Similar spikes are also seen in the turbulent cases with $l_{T}$ of $1 \mathrm{~mm}$ and $5 \mathrm{~mm}$. The high-pressure spikes stem from the collision of multiple developing detonation waves, which do not evolve into fully developed denotations, and/or emerging autoignition waves near the end of the intense turbulent combustion process.

\subsection{Quantitative diagnostics of knock intensity}

In previous sections, $F_{H}, F_{C J}$, and $F_{V N}$ have been used to quantitatively characterize the combustion intensity. The temporal evolution of $F_{H}$ and $F_{V N}\left(F_{C J}\right.$ not shown here) together with the temporal evolution of the volume-averaged HRR are further examined to discern the combustion modes for all the cases, as plotted in Figs. 11 and 12. Two main points are made from these figures.

First, the cases with high turbulent intensity feature a higher peak $\operatorname{HRR}$ (i.e., $\mathrm{G}_{1}^{1}, \mathrm{G}_{2}^{1}$, and $\mathrm{E}_{2}^{1} 3 \mathrm{D}$ ) that is attributed to the acceleration of a faster turbulent ignition front speed at the early phase of combustion, which increases both temperature and pressure of the end-gas more rapidly, leading to a more intense spontaneous ignition process with high-pressure spikes. The latter originates from collisions of multiple spontaneous ignition fronts at the late combustion phase (after the peak HRR). Second, the $F_{V N}$ profiles reveal that for all the cases with $l_{T}=5 \mathrm{~mm}$, high-pressure detonation waves are formed at the early combustion phase prior to the peak of HRR, while for the cases with smaller $l_{T}$ of $1 \mathrm{~mm}$ and $2 \mathrm{~mm}$, detonation waves are clearly observed only after the peak of HRR when the pressure and tem- 

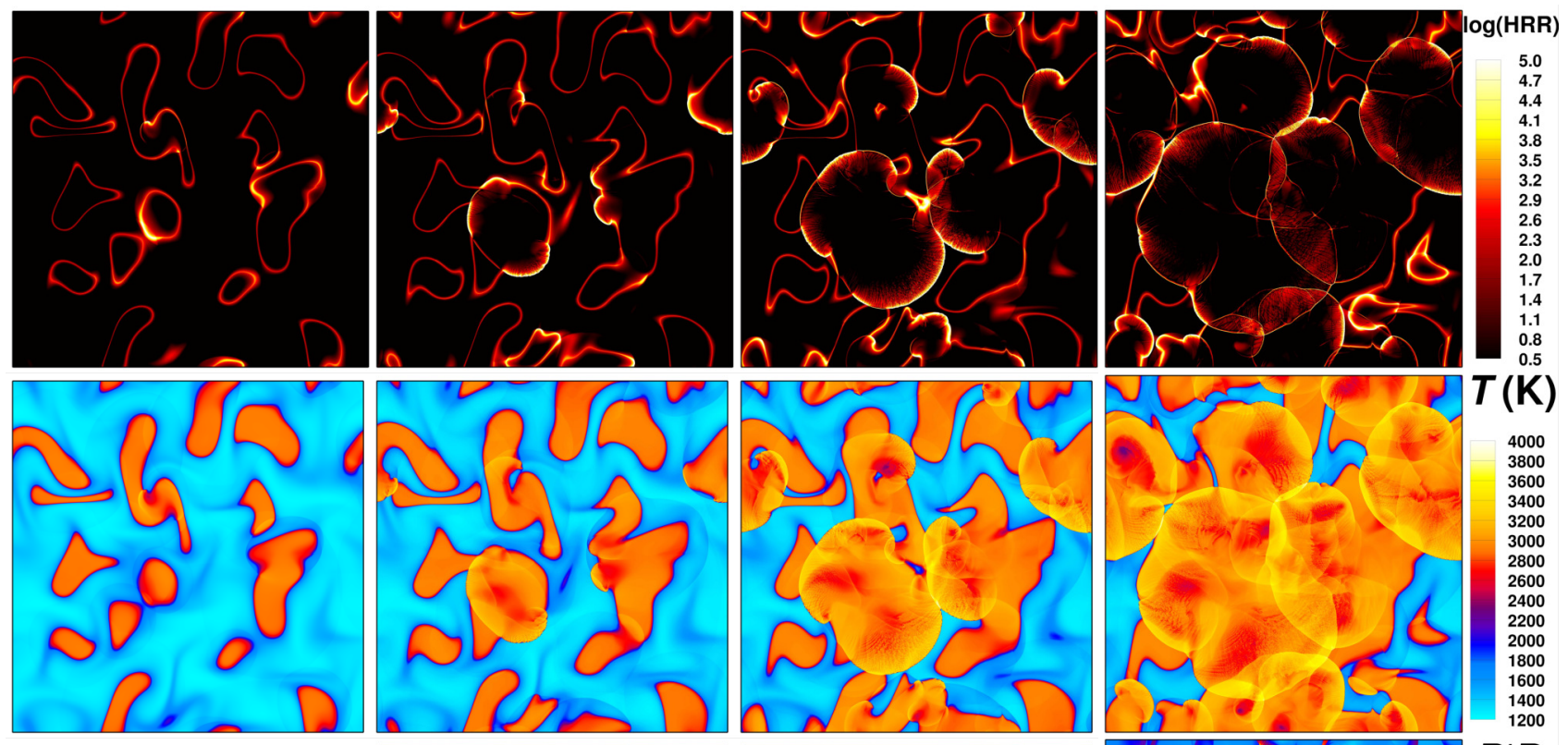

$T(\mathrm{~K})$
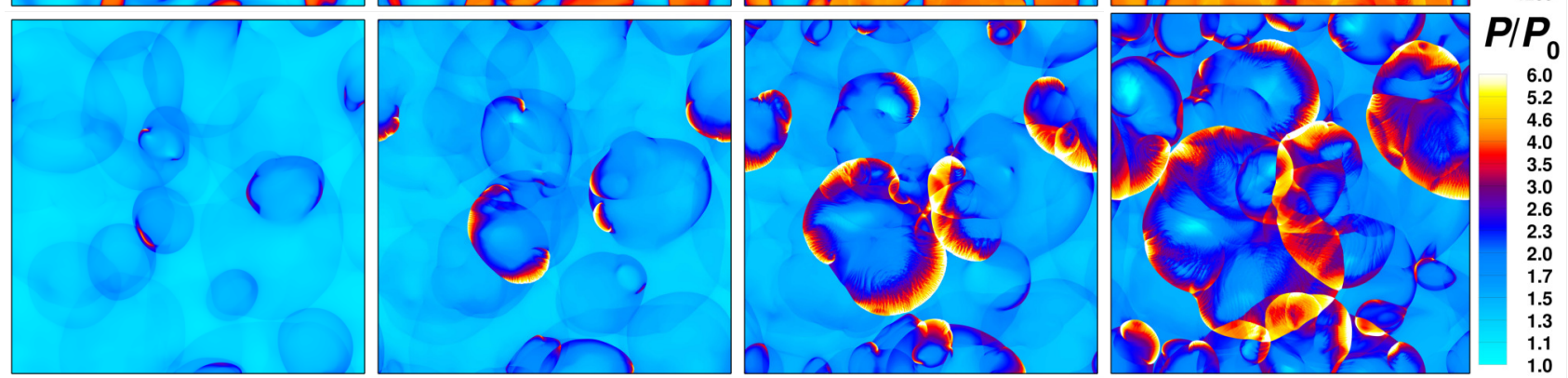

Fig. 7: Instantaneous contours of HRR (top row), temperature (middle row), and pressure (bottom row) for $\mathrm{L}_{5}^{5}$ $\left(l_{T}=l_{e}=5 \mathrm{~mm}, u^{\prime}=16.6 \mathrm{~m} / \mathrm{s}\right.$, and $\left.\tau_{i g} / \tau_{t}=0.2\right)$ with increasing time from left to right.

perature are high enough to facilitate the detonation initiation. $F_{H}, F_{C J}$, and $F_{V N}$ of all the cases from the previous study without turbulence [52], as well as those from this study are compiled and plotted in Fig. 13. Again, a significant level of $F_{V N}$ implies that shockto-shock interactions lead to a more detrimental knock events with higher pressure peaks. A good correlation is observed for $F_{H}$ and $F_{C J}$ regardless of the different curvature effects of 2-D and 3-D cases and the effects of turbulence. The correlation of $F_{H}$ and $F_{V N}$ shows some level of scatters due to various factors including the variation of $l_{T}, l_{e}$, the magnitude of $T^{\prime}$, and also the multi-dimensional 2-D and 3-D curvature effect as seen in Fig. 13b and Table 1 for BL5 and $\mathrm{BL}_{5} 3 \mathrm{D}$ with $F_{V N}$ of 0.2 and 0.1 , respectively. These correlations suggest that the detonability of the mixture increases with increasing the amount of unburnt mixture in the end gas. In particular, a sufficient amount of the remaining charge, i.e., $F_{H} \geq 0.3$, is required to induce a high super-knock intensity.

\section{Conclusions}

The effects of turbulence on the knock formation of a stoichiometric ethanol/air mixture under the endgas autoignitive conditions relevant to IC engines were investigated using multi-dimensional direct numerical simulations and a 40-species skeletal mechanism. Parametric simulations were performed by systematically varying the most energetic length scale of temperature, $l_{T}$, and of turbulence, $l_{e}$, and varying the velocity fluctuation levels, $u^{\prime}$. It was found that $l_{T} / l_{e}$ and $\tau_{i g} / \tau_{t}$ are the key parameters to affect the detonation propensity. The detonation propensity increases with increasing either $l_{T}$ or $l_{e}$ as both effects allow a larger run-up distance for the detonation development. High turbulence intensity achieved by a large $l_{e}$ and a large $u^{\prime}$, i.e., $l_{T} / l_{e}=0.2$ and $\tau_{i g} / \tau_{t}=1$, effectively modifies the characteristic length scale of the initial temperature field, $l_{T}$, to a broader range that allows a longer run-up distance for developing detonation, thereby increasing the likelihood of the detonation formation. On 

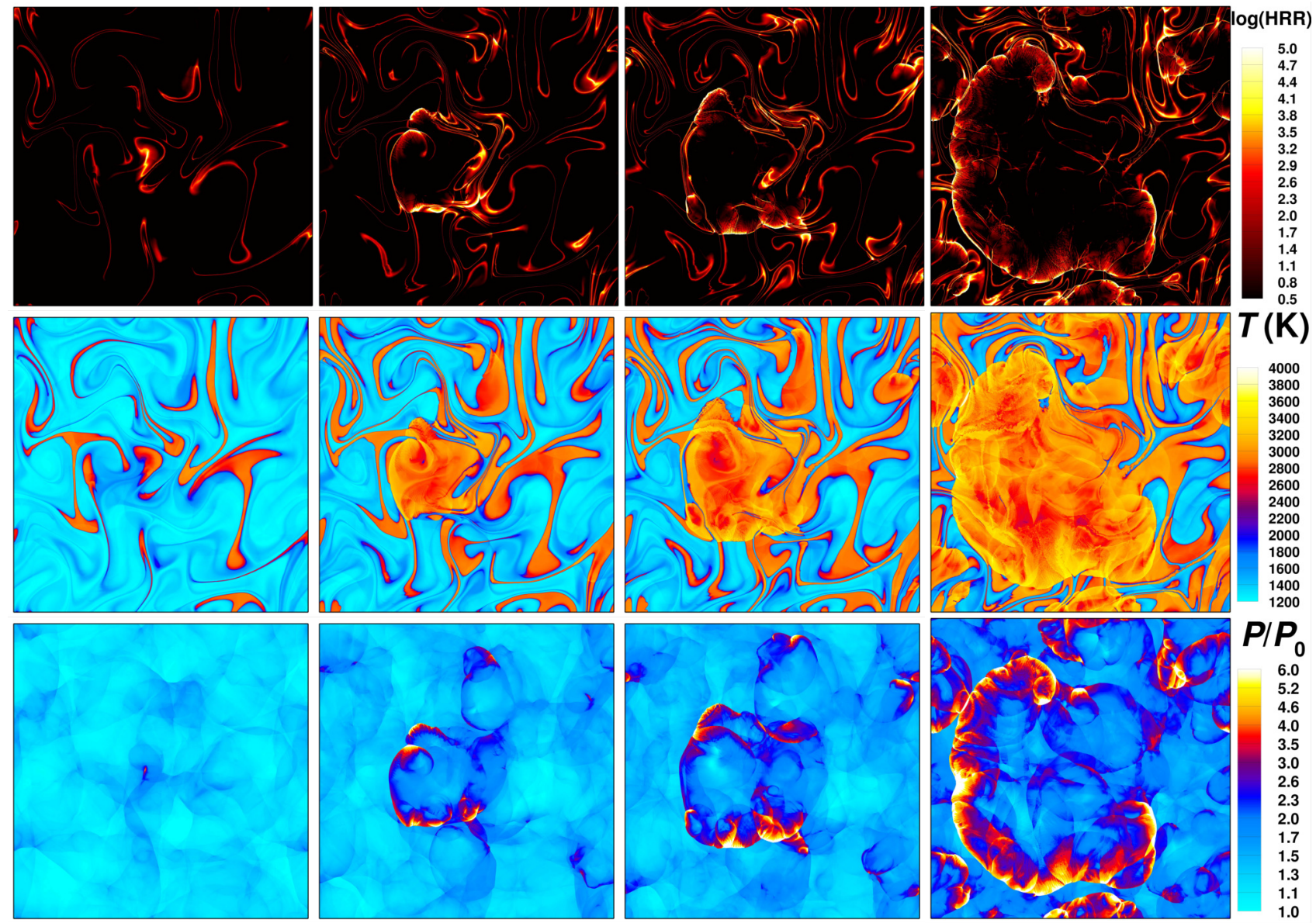

Fig. 8: Instantaneous contours of $\operatorname{HRR}$ (top row), temperature (middle row), and pressure (bottom row) for $\mathrm{E}_{5}^{5}$ $\left(l_{T}=l_{e}=5 \mathrm{~mm}, u^{\prime}=83.3 \mathrm{~m} / \mathrm{s}\right.$, and $\left.\tau_{i g} / \tau_{t}=1\right)$ with increasing time from left to right.

the contrary, high turbulence intensity achieved by a small $l_{e}$ and a large $u^{\prime}$, i.e., $l_{T} / l_{e}=5$ and $\tau_{i g} / \tau_{t}=5$, results in a faster mixing time scale of turbulence which in turn effectively decreases $l_{T}$ in time, thereby reducing the detonation intensity. No significant mitigation of super-knock intensity was observed with either $\tau_{i g} / \tau_{t}$ less than unity or $l_{e}=l_{T}$ even with a large $u^{\prime}$. It was also found that high turbulent intensity may induce high-pressure spikes comparable to the von Neumann spike. The localized pressure spikes are found to occur noticeably after the peak of the heat release rate at which the increased temperature and pressure enhance the collision and interaction of multiple emerging autoignition fronts near the ending combustion process, which in turn significantly facilitates the detonation formation.

Future work is needed to study the ignition characteristics of higher hydrogen fuels exhibiting the NTC behavior which modifies $\partial \tau_{i g} / \partial T$, which would lead to more complex interactions between turbulence and cool/hot flames involving additional time scales from multistage autoignition [30, 32, 33, 39, 50].

\section{Acknowledgments}

This work was sponsored by King Abdullah University of Science and Technology (KAUST) and used the computational resources of the KAUST Supercomputing Laboratory.

\section{Conflict of Interest}

The authors declare that they have no conflict of interest. 

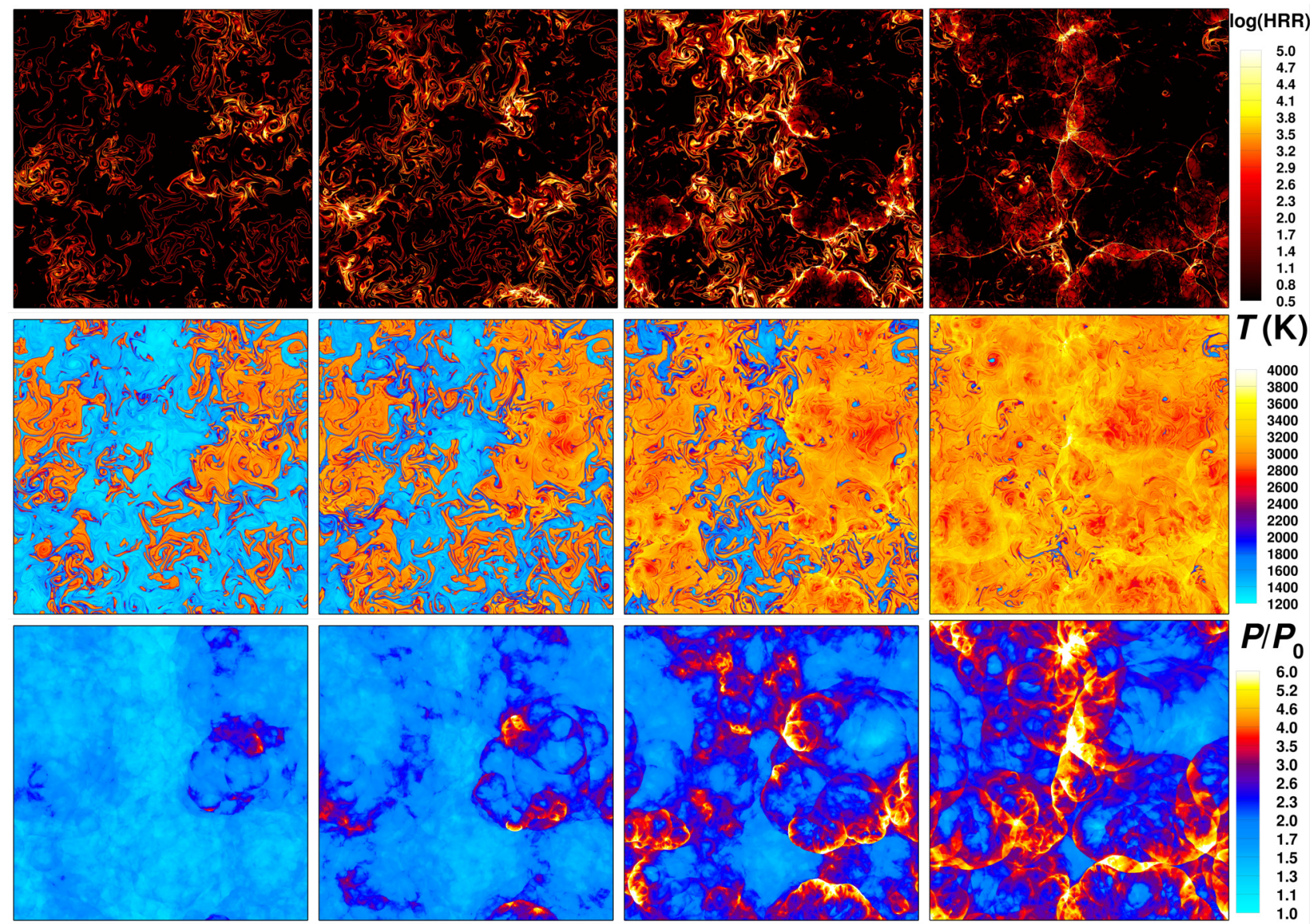

Fig. 9: Instantaneous contours of HRR (top row), temperature (middle row), and pressure (bottom row) for $\mathrm{G}_{5}^{1}$ $\left(l_{T}\right.$ of $5 \mathrm{~mm}, l_{e}$ of $1 \mathrm{~mm}, u^{\prime}$ of $83.3 \mathrm{~m} / \mathrm{s}$, and $\tau_{i g} / \tau_{t}$ of 5.0$)$ with increasing time from left to right.
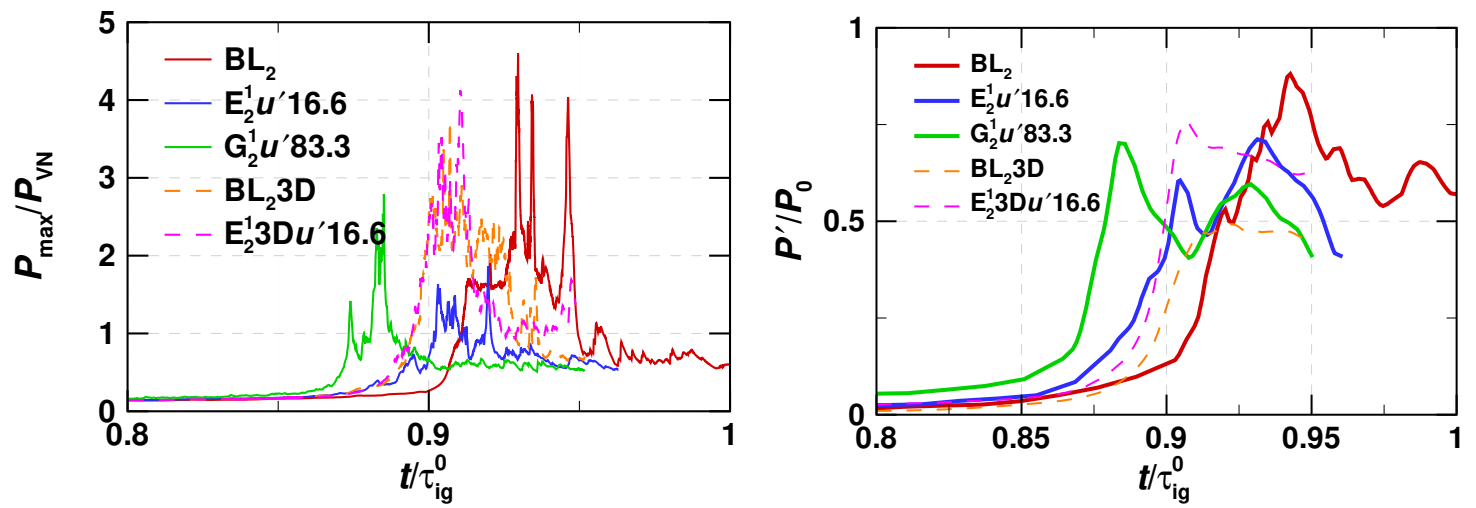

Fig. 10: Temporal evolution of the normalized maximum pressure, $P_{\max } / P_{V N}$, and the normalized root-meansquare pressure fluctuation, $P^{\prime} / P_{0}$ for the cases with $l_{e}$ of $2 \mathrm{~mm}$. 

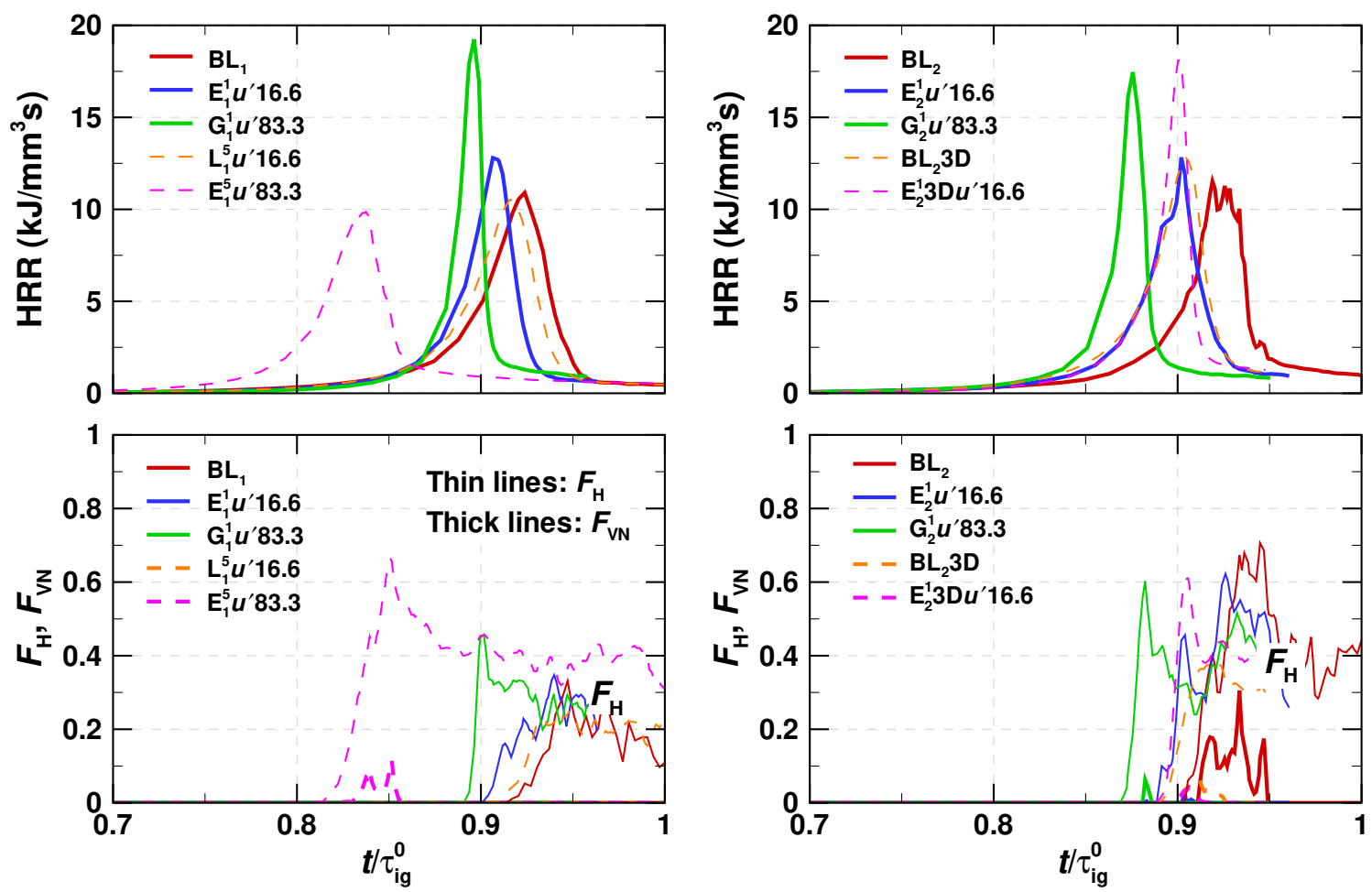

Fig. 11: Temporal evolution of the heat release rate (HRR), and the fraction of HRR from the regions with pressure greater than $1.1 P_{e}$ and $P_{V N}, P_{H}$ and $P_{V N}$, respectively, for the cases with $l_{T}$ of $1 \mathrm{~mm}$ and $2 \mathrm{~mm}$.
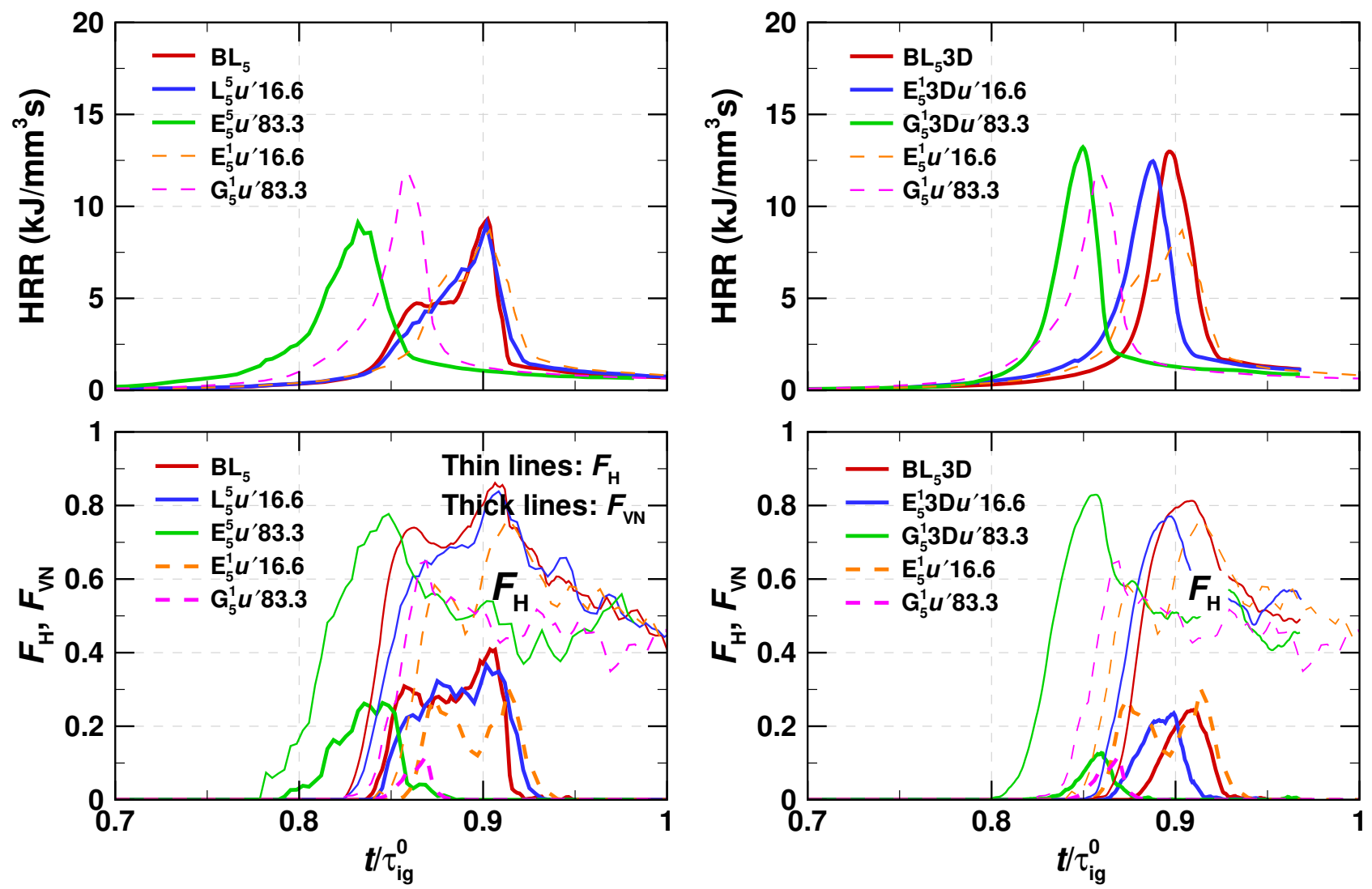

Fig. 12: Temporal evolution of the heat release rate (HRR), and the fraction of HRR from the regions with pressure greater than $1.1 P_{e}$ and $P_{V N}, P_{H}$ and $P_{V N}$, respectively, for the cases with $l_{T}$ of $5 \mathrm{~mm}$. 

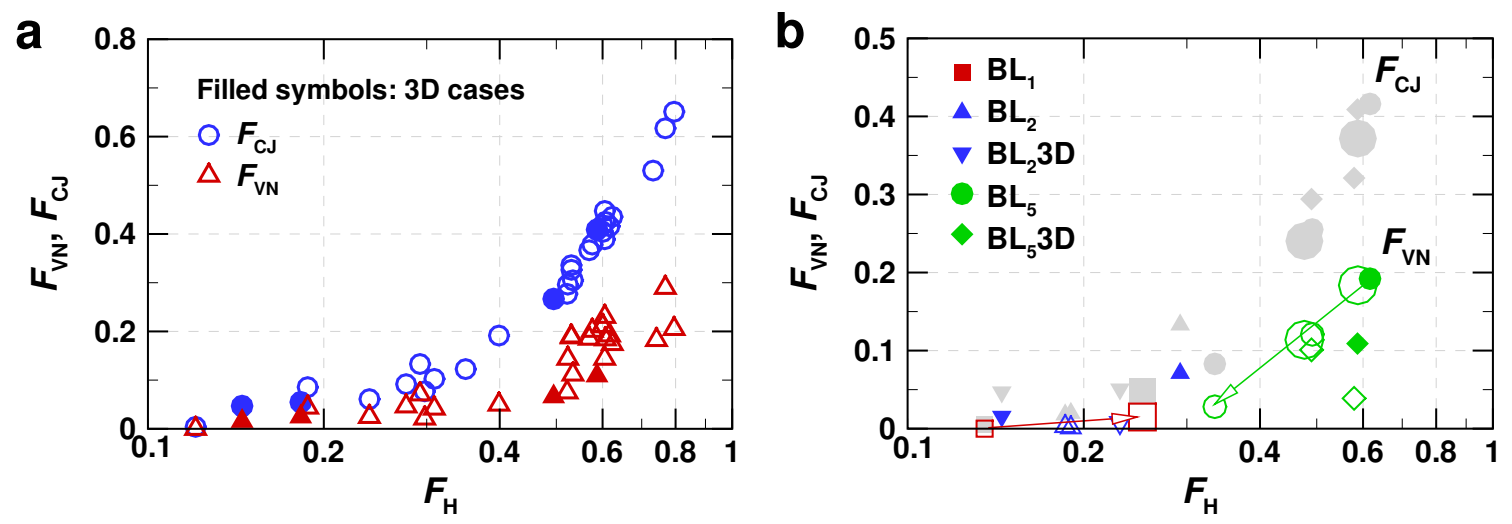

Fig. 13: $F_{V N}$ and $F_{C J}$ as a function of $F_{H}$ for the cases (a) from [52] without turbulence, and (b) this study with turbulence. In the right figure, the turbulent cases with $l_{e}$ of $5 \mathrm{~mm}(1 \mathrm{~mm})$ are marked by the big (small) open symbols while the filled symbols correspond to baseline cases. Note that each point corresponds to one DNS simulation. 


\section{References}

1. Z. Wang, H. Liu, R. D. Reitz, Knocking combustion in spark-ignition engines, Prog. Energy Combust. Sci. 61 (2017) 78-112.

2. Gautam T Kalghatgi, Derek Bradley, Pre-ignition and 'super-knock' in turbo-charged spark-ignition engines, Int. J. Engine Res. 13 (2012) 399-414.

3. Y. B. Zeldovich, Regime classification of an exothermic reaction with nonuniform initial conditions, Combust. Flame 39 (1980) 211-214.

4. P. Urtiew, A. Oppenheim, Experimental observations of the transition to detonation in an explosive gas, Proc. R. Soc. London Ser. A 295 (1966) 13-28.

5. J. W. Meyer, A. K. Oppenheim, On the shock-induced ignition of explosive gases, Symp. (Int.) Combust. 13 (1971) 1153-1164.

6. A. E. Lutz, R. J. Kee, J. A. Miller, H. A. Dwyer, A. K. Oppenheim, Dynamic effects of autoignition centers for hydrogen and c1,2-hydrocarbon fuels, Symp. (Int.) Combust. 22 (1989) 1683-1693.

7. D. Bradley, C. Morley, X. J. Gu, D. R. Emerson, Amplified pressure waves during autoignition: Relevance to CAI engines, SAE Technical Paper (2002) 2002-01-2868.

8. X. Gu, D. Emerson, D. Bradley, Modes of reaction front propagation from hot spots, Combust. Flame 133 (2003) $63-74$.

9. L. Bates, D. Bradley, G. Paczko, N. Peters, Engine hot spots: Modes of auto-ignition and reaction propagation, Combust. Flame 166 (2016) 80-85.

10. L. Bates, D. Bradley, Deflagrative, auto-ignitive, and detonative propagation regimes in engines, Combust. Flame 175 (2017) 118-122.

11. N. Peters, B. Kerschgens, G. Paczko, Super-knock prediction using a refined theory of turbulence, SAE Int. J. Engines 6 (2013) 953-967.

12. P. Dai, Z. Chen, S. Chen, Y. Ju, Numerical experiments on reaction front propagation in n-heptane/air mixture with temperature gradient, Proc. Combust. Inst. 35 (2015) 3045-3052.

13. H. Yu, Z. Chen, End-gas autoignition and detonation development in a closed chamber, Combust. Flame 162 (2015) 4102-4111.

14. P. Dai, C. Qi, Z. Chen, Effects of initial temperature on autoignition and detonation development in dimethyl ether/air mixtures with temperature gradient, Proc. Combust. Inst. 36 (2017) 3643-3650.

15. H. Terashima, A. Matsugi, M. Koshi, Origin and reactivity of hot-spots in end-gas autoignition with effects of negative temperature coefficients: Relevance to pressure wave developments, Combust. Flame 184 (2017) 324-334.

16. J. Pan, H. Wei, G. Shu, Z. Chen, P. Zhao, The role of low temperature chemistry in combustion mode development under elevated pressures, Combust. Flame 174 (2016) 179-193.

17. J. Pan, H. Wei, G. Shu, R. Chen, Effect of pressure wave disturbance on auto-ignition mode transition and knocking intensity under enclosed conditions, Combust. Flame 185 (2017) 63-74.

18. H. Wei, C. Chen, G. Shu, X. Liang, L. Zhou, Pressure wave evolution during two hotspots autoignition within end-gas region under internal combustion engine-relevant conditions, Combust. Flame 189 (2018) 142-154.

19. J. Pan, S. Dong, H. Wei, T. Li, G. Shu, L. Zhou, Temperature gradient induced detonation development inside and outside a hotspot for different fuels, Combust. Flame 205 (2019) 269-277.
20. A. Sow, B. J. Lee, F. E. Hernández Pérez, H. G. Im, Detonation onset in a thermally stratified constant volume reactor, Proc. Combust. Inst. 37 (2019) 3529-3536.

21. S. Desai, R. Sankaran, H. G. Im, Unsteady deflagration speed of an auto-ignitive dimethyl-ether (DME)/air mixture at stratified conditions, Proc. Combust. Inst. 37 (2019) 4717 - 4727

22. S. Desai, R. Sankaran, H. G. Im, Auto-ignitive deflagration speed of methane $\left(\mathrm{CH}_{4}\right)$ blended dimethyl-ether (DME)/air mixtures at stratified conditions, Combust. Flame 211 (2020) 377 - 391.

23. A. Robert, S. Richard, O. Colin, L. Martinez, L. De Francqueville, LES prediction and analysis of knocking combustion in a spark ignition engine, Proc. Combust. Inst. 35 (2015) 2941-2948.

24. A. Robert, S. Richard, O. Colin, T. Poinsot, LES study of deflagration to detonation mechanisms in a downsized spark ignition engine, Combust. Flame 162 (2015) 2788 2807.

25. R. Sankaran, H. G. Im, E. R. Hawkes, J. H. Chen, The effects of non-uniform temperature distribution on the ignition of a lean homogeneous hydrogen-air mixture, Proc. Combust. Inst. 30 (2005) 875-882.

26. J. H. Chen, E. R. Hawkes, R. Sankaran, S. D. Mason, H. G. Im, Direct numerical simulation of ignition front propagation in a constant volume with temperature inhomogeneities: I. fundamental analysis and diagnostics, Combust. Flame 145 (2006) 128-144.

27. E. R. Hawkes, R. Sankaran, P. Pébay, J. H. Chen, Direct numerical simulation of ignition front propagation in a constant volume with temperature inhomogeneities: II. parametric study, Combust. Flame 145 (2006) 145-159.

28. G. Bansal, H. G. Im, Autoignition and front propagation in low temperature combustion engine environments, Combust. Flame 158 (2011) 2105-2112.

29. S. Gupta, H. G. Im, M. Valorani, Classification of ignition regimes in HCCI combustion using computational singular perturbation, Proc. Combust. Inst. 33 (2011) 29912999.

30. C. S. Yoo, T. Lu, J. H. Chen, C. K. Law, Direct numerical simulations of ignition of a lean $n$-heptane/air mixture with temperature inhomogeneities at constant volume: Parametric study, Combust. Flame 158 (2011) $1727-1741$.

31. R. Yu, X.-S. Bai, Direct numerical simulation of lean hydrogen/air auto-ignition in a constant volume enclosure, Combust. Flame 160 (2013) 1706-1716.

32. H. A. El-Asrag, Y. Ju, Direct numerical simulations of exhaust gas recirculation effect on multistage autoignition in the negative temperature combustion regime for stratified HCCI flow conditions by using $\mathrm{H}_{2} \mathrm{O}_{2}$ addition, Combust. Theory Model. 17 (2013) 316-334.

33. H. A. El-Asrag, Y. Ju, Direct numerical simulations of $\mathrm{NO}_{\mathrm{x}}$ effect on multistage autoignition of DME/air mixture in the negative temperature coefficient regime for stratified HCCI engine conditions, Combust. Flame 161 (2014) 256-269.

34. A. Bhagatwala, T. Lu, J. H. Chen, Direct numerical simulations of HCCI/SACI with ethanol, Combust. Flame 161 (2014) 1826-1841.

35. A. Bhagatwala, R. Sankaran, S. Kokjohn, J. H. Chen, Numerical investigation of spontaneous flame propagation under RCCI conditions, Combust. Flame 162 (2015) $3412-3426$

36. G. Bansal, A. Mascarenhas, J. H. Chen, Direct numerical simulations of autoignition in stratified dimethylether (DME)/air turbulent mixtures, Combust. Flame 162 (2015) 688-702. 
37. C. S. Yoo, Z. Luo, T. Lu, H. Kim, J. H. Chen, A DNS study of ignition characteristics of a lean iso-octane/air mixture under and SACI conditions, Proc. Combust. Inst. 34 (2013) 2985-2993.

38. M. B. Luong, Z. Luo, T. Lu, S. H. Chung, C. S. Yoo, Direct numerical simulations of the ignition of lean primary reference fuel/air mixtures with temperature inhomogeneities, Combust. Flame 160 (2013) 2038-2047.

39. S. O. Kim, M. B. Luong, J. H. Chen, C. S. Yoo, A DNS study of the ignition of lean PRF/air mixtures with temperature inhomogeneities under high pressure and intermediate temperature, Combust. Flame 162 (2015) 717726 .

40. M. B. Luong, G. H. Yu, S. H. Chung, C. S. Yoo, Ignition of a lean PRF/air mixture under RCCI/SCCI conditions: A comparative DNS study, Proc. Combust. Inst. 36 (2017) 3623-3631.

41. G. H. Yu, M. B. Luong, S. H. Chung, C. S. Yoo, Ignition characteristics of a temporally evolving $n$-heptane jet in an iso-octane/air stream under RCCI combustionrelevant conditions,, Combust. Flame 208 (2019) 299312.

42. H. G. Im, P. Pal, M. S. Wooldridge, A. B. Mansfield, A regime diagram for autoignition of homogeneous reactant mixtures with turbulent velocity and temperature fluctuations, Combust. Sci. Technol. 187 (2015) 1263-1275.

43. P. Pal, M. Valorani, P. G. Arias, H. G. Im, M. S. Wooldridge, P. P. Ciottoli, R. M. Galassi, Computational characterization of ignition regimes in a syngas/air mixture with temperature fluctuations, Proc. Combust. Inst. 36 (2017) 3705-3716.

44. M. B. Luong, F. E. Hernández Pérez, H. G. Im, Prediction of ignition modes of NTC-fuel/air mixtures with temperature and concentration fluctuations, Combust. Flame 213 (2020) 382-393.

45. M. B. Luong, F. E. Hernández Pérez, A. Sow, H. G. $\mathrm{Im}$, Prediction of ignition regimes in DME/air mixtures with temperature and concentration fluctuations, AIAA SciTech 2019 Forum (2019).

46. M. J. M. Ali, M. B. Luong, A. Sow, F. E. Hernández Pérez, H. G. Im, Probabilistic approach to predict abnormal combustion in spark ignition engines, SAE paper (2018) 2018-01-1722.

47. H. Wei, C. Chen, H. Zhou, W. Zhao, Z. Ren, Effect of turbulent mixing on the end gas auto-ignition of nheptane/air mixtures under IC engine-relevant conditions, Combust. Flame 174 (2016) 25-36.

48. L. Chen, H. Wei, C. Chen, D. Feng, L. Zhou, J. Pan, Numerical investigations on the effects of turbulence intensity on knocking combustion in a downsized gasoline engine, Energy 166 (2019) 318-325.

49. L. Zhong, C. Liu, Numerical analysis of end-gas autoignition and pressure oscillation in a downsized SI engine using large eddy simulation, Energies 12 (2019) 3909.

50. T. Zhang, W. Sun, L. Wang, Y. Ju, Effects of lowtemperature chemistry and turbulent transport on knocking formation for stratified dimethyl ether/air mixtures, Combust. Flame 200 (2019) 342-353.

51. C. A. Z. Towery, A. Y. Poludnenko, P. E. Hamlington, Detonation initiation by compressible turbulence thermodynamic fluctuations, Combust. Flame 213 (2020) 172183.

52. M. B. Luong, S. Desai, F. E. Hernández Pérez, R. Sankaran, B. Johansson, H. G. Im, A statistical analysis of developing knock intensity in a mixture with temperature inhomogeneities, Accepted for presentation at the 38th Inst. Symp. on Combust. (2019).
53. M. Figueroa-Labastida, J. Badra, A. M. Elbaz, A. Farooq, Shock tube studies of ethanol preignition, Combust. Flame 198 (2018) 176-185.

54. F. E. Hernández Pérez, N. Mukhadiyev, X. Xu, A. Sow, B. J. Lee, R. Sankaran, H. G. Im, Direct numerical simulations of reacting flows with detailed chemistry using many-core/GPU acceleration, Computers \& Fluids 173 (2018) 73-79.

55. S. Desai, J. K. Yu, W. Song, M. B. Luong, F. E. Hernández Pérez, R. Sankaran, H. G. Im, Direct numerical simulations of reacting flows with shock waves and stiff chemistry using many-core/GPU acceleration, Submitted to Computers \& Fluids (2019).

56. A. C. Hindmarsh, P. N. Brown, K. E. Grant, S. L. Lee, R. Serban, D. E. Shumaker, C. S. Woodward, SUNDIALS: Suite of nonlinear and differential/algebraic equation solvers, ACM Transactions on Mathematical Software (TOMS) 31 (3) (2005) 363-396.

57. Y. An, M. Jaasim, R. Vallinayagam, S. Vedharaj, H. G. Im, B. Johansson, Numerical simulation of combustion and soot under partially premixed combustion of lowoctane gasoline, Fuel 211 (2018) 420-431.

58. T. Passot, A. Pouquet, Numerical simulation of compressible homogeneous flows in the turbulent regime, J. Fluid Mech. 118 (1987) 441-466.

59. J. E. Dec, Advanced compression-ignition combustion for high efficiency and ultra-low $\mathrm{NO}_{\mathrm{x}}$ and soot, in: T. K. D. Crolla, D.E. Foster, N. Vaughan (Eds.), Encyclopedia of Automotive Engineering, John Wiley \& Sons, Ltd, 2014, pp. 1-40.

60. G. Mittal, C.-J. Sung, Aerodynamics inside a rapid compression machine, Combust. Flame 145 (2006) 160-180.

61. Y. Wang, C. J. Rutland, Effects of temperature and equivalence ratio on the ignition of $n$-heptane fuel spray in turbulent flow, Proc. Combust. Inst. 30 (2005) 893900.

62. S. L. Kokjohn, M. P. B. Musculus, R. D. Reitz, Evaluating temperature and fuel stratification for heat-release rate control in a reactivity-controlled compressionignition engine using optical diagnostics and chemical kinetics modeling, Combust. Flame 162 (2015) 2729-2742.

63. Q. Tang, H. Liu, M. Yao, Simultaneous measurement of natural flame luminosity and emission spectra in a RCCI engine under different fuel stratification degrees, SAE Int. J. Engines 10 (2017) 2017-01-0714.

64. R. Schießl, U. Maas, Analysis of endgas temperature fluctuations in an SI engine by laser-induced fluorescence, Combust. Flame 133 (2003) 19-27.

65. S. A. Kaiser, M. Schild, C. Schulz, Thermal stratification in an internal combustion engine due to wall heat transfer measured by laser-induced fluorescence, Proc. Combust. Inst. 34 (2013) 2911-2919.

66. F. Söderberg, B. Johansson, B. Lindoff, Wavelet analysis of in-cylinder ldv measurements and correlation against heat-release, SAE paper 107 (1998) 444-456.

67. C. Funk, V. Sick, D. L. Reuss, W. J. A. Dahm, Turbulence properties of high and low swirl in-cylinder flows, SAE paper (2002) 2002-01-2841.

68. P. C. Miles, Turbulent flow structure in direct-injection, swirl-supported diesel engines, in: Flow and Combustion in Reciprocating Engines, Experimental Fluid Mechanics, Springer, 2008, pp. 173-256.

69. V. Akkerman, M. Ivanov, V. Bychkov, Turbulent flow produced by piston motion in a spark-ignition engine, Flow Turbul. Combust. 82 (2009) 317-337.

70. B. R. Petersen, J. B. Ghandhi, High resolution scalar dissipation and turbulence length scale measurements in 
an internal combustion engine, SAE Int. J. Engines 3 (2010) 65-83. 